ANGELA MAYUMI SHIMAOKA

\title{
INFLUÊNCIA DA DELIMITAÇÃO DA ÁREA ADESIVA NO ENSAIO MECÂNICO DE MICROCISALHAMENTO
}

São Paulo

2007 
Angela Mayumi Shimaoka

Influência da delimitação da área adesiva no ensaio mecânico de microcisalhamento

Dissertação apresentada à Faculdade de Odontologia da Universidade de São Paulo, para obtenção do título de Mestre pelo Programa de Pós-Graduação em Odontologia.

Área de Concentração: Dentística

Orientador:

Prof. Dr. Rubens Côrte Real de Carvalho 


\section{FOLHA DE APROVAÇÃO}

Shimaoka AM. Influência da delimitação da área adesiva no ensaio mecânico de microcisalhamento [Dissertação de Mestrado]. São Paulo: Faculdade de Odontologia da USP; 2007.

São Paulo, / 2007

\section{Banca Examinadora}

1) $\operatorname{Prof}(a) \cdot \operatorname{Dr}(a)$.

Titulação:

Julgamento:

Assinatura:

2) $\operatorname{Prof}(a) . \operatorname{Dr}(a)$.

Titulação:

Julgamento:

Assinatura:

3) $\operatorname{Prof}(a) . \operatorname{Dr}(a)$.

Titulação:

Julgamento: Assinatura: 
"Na vida não há nada como um sonho para criar um futuro" Leonardo da Vinci 


\section{DEDICATÓRIA}

À minha mãe Berenise, mulher forte, batalhadora e dedicada. Responsável por moldar meu caráter e meus princípios. Palavras não seriam capazes de expressar minha admiração por ela, um verdadeiro exemplo para mim.

Aos meus irmãos Rita e Gabriel que me ensinaram a compartilhar e o verdadeiro significado da amizade.

Ao meu pai Osvaldo. Nosso tempo juntos foi curto mas repleto de amor e aprendizado. Saudades...

Tenho muito orgulho de fazer parte desta família.

Amo vocês 


\section{AGRADECIMENTO ESPECIAL}

À minha melhor amiga, Alesssandra Pereira de Andrade. Amiga dedicada, presente, inteligente e sensível. Capaz de inspirar o que há de melhor nas pessoas. Professora e pesquisadora nata. Responsável pelo meu ingresso na carreira acadêmica, me aconselhando, orientando e estimulando desde meu primeiro corpo de prova. Sem você teria sido impossível.

À Profa. Dra. Silvia Rosana Soares Carneiro por tudo que me ensinou. Acreditou, apostou em mim e me deu esperança, com a oportunidade de exercer a Odontologia que aprendi e acredito. Você foi, com certeza, a melhor em tudo que se propôs a fazer. Realmente "nunca se dobrou".

Ao meu orientador Prof. Dr. Rubens Côrte Real de Carvalho. Homem sábio, sinônimo de inteligência e honradez. Orientador presente e ciente do seu papel, conhece e acredita nas pessoas. Insistente, auxilia seus orientados com nossas limitações e estimula nossas qualidades. Possuidor de uma capacidade inigualável de aprender que, associada ao prazer em ensinar e transmitir seus conhecimentos e valores o tornam um verdadeiro mestre.

Ter recebido a dádiva de encontrar e conviver com pessoas como vocês me dá a certeza de que estou trilhando o caminho certo.

A vocês minhas eternas admiração e gratidão. 


\section{AGRADECIMENTOS}

Às minhas queridas amigas "Pereiras", Ivani e Larrissa. Obrigada por todo apoio e carinho. Vocês foram essenciais em todo esse processo.

Ao amigo Márcio Vivan Cardoso. Homem íntegro, dedicado, disciplinado e amigo. Suas qualidades te levaram à todas as suas conquistas. Seu caminho de sucesso está só começando. Tenho orgulho de ser sua amiga.

À bibliotecária Vânia Funaro pela normalização de referências e revisão da formatação deste trabalho.

Às Profas. Ana Cecília Corrêa Aranha e Patricia Moreira de Freitas pelo apoio na fase de microscopia eletrônica de varredura deste trabalho.

À técnica do Laboratório de Pesquisa Aplicada Soninha sempre prestativa e simpática.

Ao técnico do Centro de Ciência e Tecnologia de Materiais do Instituto de Pesquisas Energéticas e Nucleares Celso Vieira de Morais pelo auxílio na metalização das amostras para análise em microscópio eletrônico de varredura.

Ao Haroldo, técnico do Laboratório Especial de Lasers em Odontologia, por ter operado o Microscópio Eletrônico de Varredura para a realização das eletromicrografias desta dissertação. 
Aos secretários do Departamento de Dentística David e Ana e da secretaria de Pósgraduação Catia e Alessandra pelo suporte durante todo o curso.

À Vilma Fontolan Quevedo por todo apoio e compreensão.

À Lourdes e Lenira por todo o carinho e dedicação.

Aos amigos Márcio Garcia e Flávio Merichello por todos os momentos agradáveis compartilhados nos últimos anos.

À minhas amigas Angela, Laila, Lika, Mila, Palmieri e Tatu. Umas mais fisicamente presente que outras, mas todas certamente sempre comigo me apoiando e torcendo muito por mim.

Ao Felipe, uma nova alegria na minha vida. 
Shimaoka AM. Influência da delimitação da área adesiva no ensaio mecânico de microcisalhamento [Dissertação de Mestrado]. São Paulo: Faculdade de Odontologia da USP; 2007.

\section{RESUMO}

Este estudo teve como objetivos avaliar se a delimitação da área adesiva a ser testada no ensaio mecânico de microcisalhamento é capaz de alterar os resultados de resistência de união obtidos; determinar se a delimitação da área adesiva do ensaio mecânico de microcisalhamento pode alterar o ranqueamento dos sistemas adesivos analisados e correlacionar os tipos de fratura encontrados com valores de resistência adesiva obtidos em cada um dos grupos experimentais. As unidades experimentais foram confeccionadas sobre 18 superfícies de dentina obtidas a partir de incisivos bovinos distribuídas aleatoriamente em 3 grupos, segundo o sistema adesivo a ser utilizado (Adper Single Bond 2, Clearfil Se Bond, Clearfil S3 Bond). Desta forma foram compostos 6 grupos experimentais segundo os dois fatores de variação a serem estudados: sistema adesivo e delimitação da área adesiva. Sobre cada superfície dentinária foram confeccionados 4 cilindros em resina composta, sendo 2 com delimitação da área adesiva e 2 sem a delimitação desta área, totalizando $n=12$. Após 24 horas de armazenamento os espécimes foram submetidos ao ensaio mecânico de microcisalhamento. O teste estatístico ANOVA $(p<0,01)$ e o teste auxiliar de Tukey determinaram que todos os grupos experimentais em que a delimitação da área adesiva foi realizada apresentaram menores valores de resistência adesiva quando comparados aos seus respectivos grupos controle (sem delimitação da área adesiva). 
Para os grupos em que não foi realizada a delimitação da área não foram observadas diferenças estatisticamente significantes entre os adesivos empregados. Em contrapartida, quando não foi realizada a delimitação, o sistema adesivo Clearfil $S^{3}$ Bond mostrou maiores valores de resistência adesiva quando comparado aos sistemas Adper Single Bond 2 e Clearfil SE Bond, que por sua vez não se mostraram estatisticamente diferentes entre si. Concluiu-se que a delimitação da área adesiva no ensaio de microcisalhamento alterou os resultados de resistência adesiva obtidos, e que a modificação da metodologia do ensaio mecânico de microcisalhamento foi capaz de alterar o ranqueamento dos sistemas adesivos analisados.

Palavras-Chaves: microcisalhamento, resistência adesiva, adesivos, delimitação de área 
Shimaoka AM. Evaluation of adhesive area delimitation on microshear test [Dissertação de Mestrado]. São Paulo: Faculdade de Odontologia da USP; 2007.

\section{ABSTRACT}

This study had as objectives to evaluate if the delimitation of adhesive area on microshear test is capable to modify the values of shear bond strength; to determine if this delimitation can modify the ranking of the analyzed adhesive systems and to correlate the found types of failure with the values of bond strength in each experimental group. The specimens were confectioned on 18 incisors bovine dentine surfaces randomly distributed into 3 groups, according to adhesive system used (Adper Single Bond 2, Clearfil If Bond, Clearfil S3 Bond). In such a way, 6 experimental groups were designed according to two factors of variation to be studied: adhesive system and delimitation of the adhesive area. Over each dentin surface were confectioned 4 composite resin cylinders, being 2 with delimitation of the adhesive area and 2 without the delimitation of this area, totalizing $n=12$. After 24 hours of storage the specimens were submitted to microshear test Statistical test ANOVA $(p<0,01)$ and Tukey's test determined that all the experimental groups where the delimitation of the adhesive area was carried through presented lesser values of shear bond strength when compared with its respective control groups (without delimitation of adhesive area). Groups without area delimitation did not been demonstrate statistical significant differences between adhesives. On the other hand, when such delimitation was not carried through, the adhesive system Clearfil $S^{3}$ Bond demonstrates greater values of shear bond strength 
compared to Adper Single 2 Bond and Clearfil SE Bond, which did not showed statistical difference between them. It was concluded that the delimitation of the adhesive area in the microshear test altered the obtained results of adhesive resistance, and that the modification of microshear test methodology was capable to modify the ranking of the analyzed adhesive systems.

Keywords: microshear, adhesives, area delimitation, shear bond strength 


\section{LISTA DE ILUSTRAÇÕES}

Figura 2.1 - Microscopias eletrônica de varredura da (A) dentina humana com aumento de 12.500x, (B) dentina bovina com aumento de 6000x (adaptado de Tagami et al., 1989).

Figura 2.2 - Microscopias eletrônicas de trasmissão evidenciando (A) a formação de árvores de água (water trees) e (B) e a permeabilidade da membrana de adesivo (Tay e Pashley, 2003b)

Figura 2.3 - Esquema ilustrativo do ensaio mecânico de microcisalhamento gentilmente cedido pelo Prof.Dr. Junji Tagami.(A) preparo da unidade experimental.(B) amostra submetida a força de cisalhamento.

Figura 4.1 - Esquema de formação dos grupos experimentais segundo os fatores de variação.

Quadro 4.1 - Composição química e protocolo de aplicação segundo seus respectivos fabricantes dos sistemas adesivos utilizados.

Figura 4.2 - Esquema representativo da fase experimental. A - seleção dos dentes bovinos; B - aplainamento das faces palatina e vestibular e obtenção da superfície dentinária; $\mathrm{C}$ - Obtenção dos fragmentos, cortes cerical e incisal; D - delimitação da área adesiva; E - procedimento a desivo; $\mathrm{F}$ - confecção dos cilindros em resina composta e ensaio mecânico de microcisalhamento.

Gráfico 5.1 - Valores médios e desvios-padrão dos grupos experimentais .50

Grafico 5.2 - Análise do padrão de fratura após realização do teste de microcisalhamento conforme as variáveis estudadas

Gráfico 5.3 - Distribuição dos tipos de fratura no teste de microcisalhamento .52 
Gráfico 5.4 - Distribuição dos tipos de fratura no teste de microcisalhamento segundo o fator de variação delimitação da área adesiva

Figura 6.1 - Eletromicrografia evidenciando o arrancamento de adesivo além dos limites definidos pelo cilindro de resina composta

Figura 6.2 - Eletromicrografia de um espécime sem delimitação de área adesiva. (A) camada de sistema adesivo, (T) porção ocupada pelo tubo tygon, (R) cilindro de resina composta.

Figura 6.3 - Imagem da amostra experimental (A) e sua respectiva eletromicrografia (B).... .58

Figura 6.4 - Eletromicrografias das superfícies dentinárias tratadas pelos sistemas adesivos utilizados neste estudo. (A) Adper single Bond 2, (B) Clearfil SE Bond, (C) Clearfil S3 Bond 


\section{LISTA DE TABELAS}

Tabela 5.1 - Teste de aderência à curva de normalidade ....................................47

Tabela 5.2 - Resultado do teste ANOVA para dois fatores de variação....................48

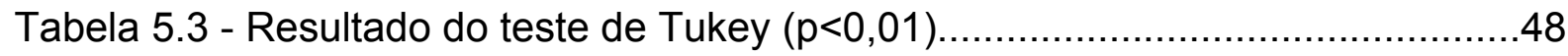

Tabela 5.4 - Resultados do teste de microcisalhamento por grupo experimental......49 


\section{LISTA DE ABREVIATURAS, SIGLAS E SÍMBOLOS}

\begin{tabular}{|c|c|}
\hline 10-MDP & 10-metacriloiloxidecil diidrogeno fosfato \\
\hline Bis-GMA & bisfenol glicidil metacrilato \\
\hline CVD & chemical vapor deposition \\
\hline DP & desvio-padrão \\
\hline Er,Cr:YSGG & Érbio, Cromo (Ítrio, Escândio, Gálio, Granada) \\
\hline GPDM & dimetacrilato de glicerol-fosfato ácido \\
\hline$n$ & número de repetições \\
\hline$\%$ & Porcentagem \\
\hline$\leq$ & menor ou igual \\
\hline $\mathrm{pH}$ & potencial hidrogênionico \\
\hline$\approx$ & Semelhante \\
\hline$\mu \mathrm{m}$ & Micrometro \\
\hline $\mathrm{mm}$ & Milimetro \\
\hline $\mathrm{mm} / \mathrm{min}$ & milimetro por minuto \\
\hline$n^{0}$ & Número \\
\hline$\varnothing$ & Diâmetro \\
\hline $\mathrm{cm}$ & Centímetro \\
\hline $\mathrm{mL}$ & Mililitos \\
\hline${ }^{\circ} \mathrm{C}$ & grau Celsius \\
\hline $\mathrm{MPa}$ & MegaPascal \\
\hline
\end{tabular}


$\mathrm{mm}^{2}$

MEV milimetro quadrado

Microscopia Eletrônica de Varredura 


\section{SUMÁRIO}

p.

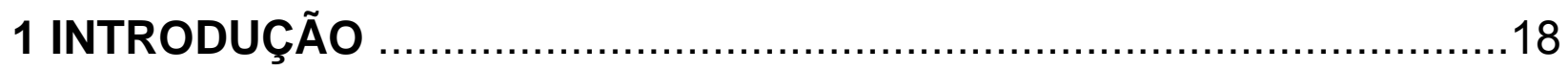

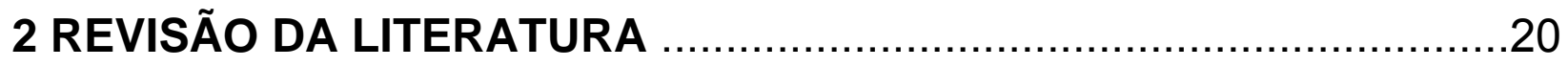

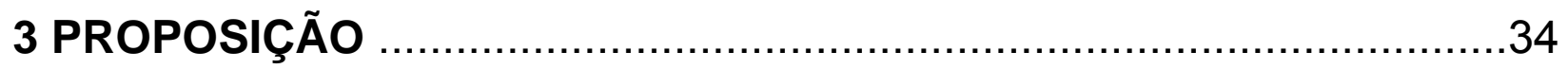

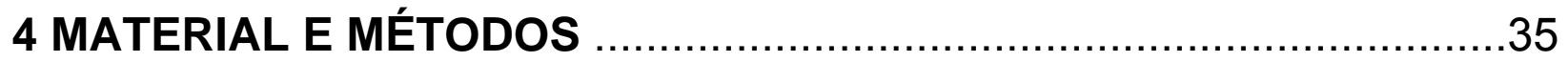

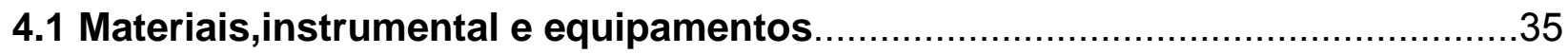

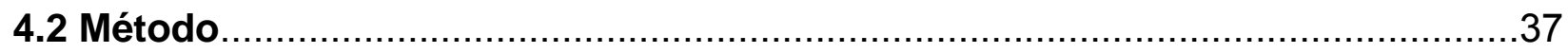

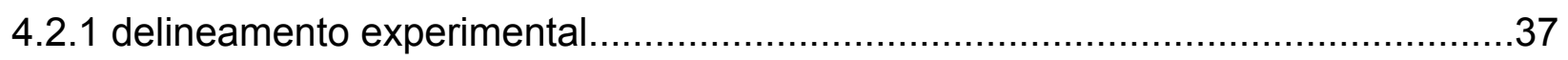

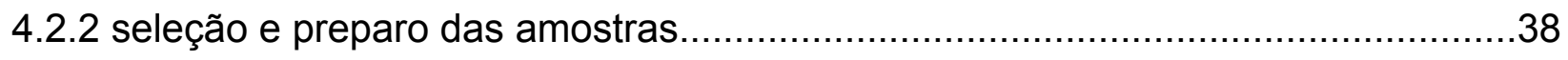

4.2 .3 confecção das unidades experimentais................................................39

4.2.4 ensaio mecânico de microcisalhamento.................................................

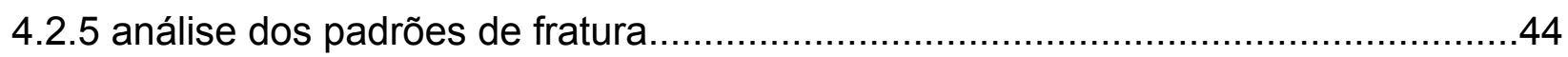

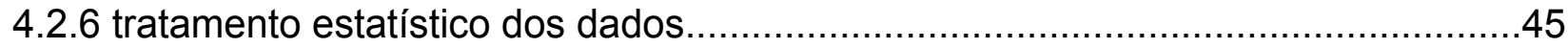

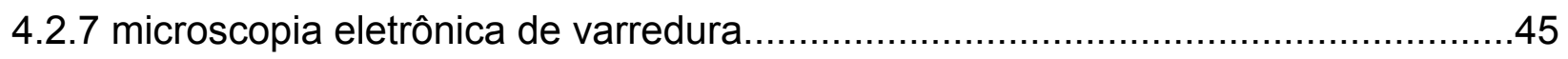

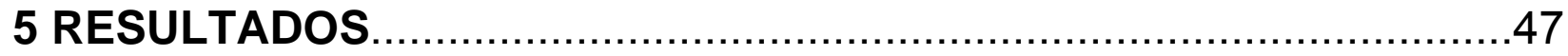

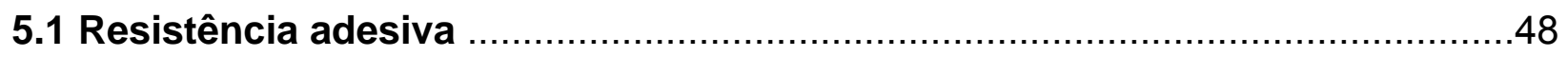

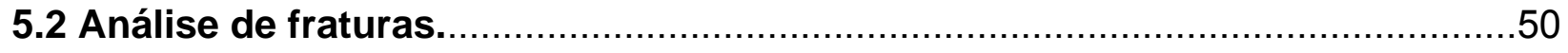

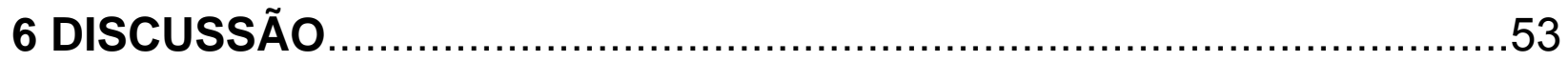

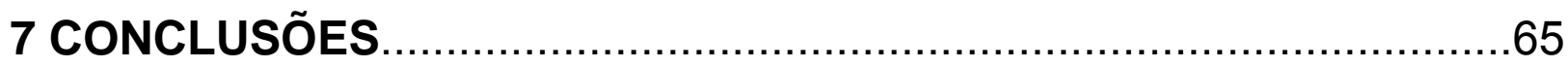

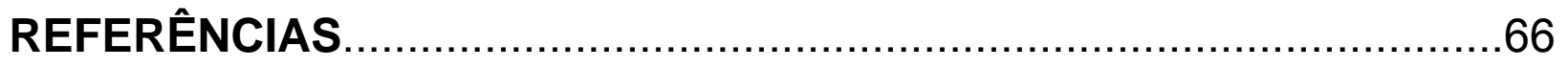

ANEXO 


\section{INTRODUÇÃo}

Os primeiros passos em direção à Odontologia Adesiva foram dados por Oskar Hagger (1949) que desenvolveu um monômero adesivo, primeiramente utilizado por McLean e Kramer (1952), e por Buonocore (1955) que preconizou o condicionamento ácido do esmalte dental (HENOSTROZA, 2003). Desde então muitas transformações têm sido observadas na Dentística Restauradora tanto por pesquisadores quanto por clínicos.

Qualidade, estabilidade e longevidade são as características almejadas na união entre material restaurador e substrato dental. São esses elementos que indicam o sucesso de uma restauração estética. Assim as modificações nos materiais e procedimentos restauradores sempre são efetuados com o objetivo de contemplar essas três necessidades.

Para que os materiais possam ser utilizados na clínica há a necessidade de avaliação do seu desempenho. Estudos clínicos longitudinais são complexos e demorados. Desta forma estudos laboratoriais são utilizados como uma ferramenta para predizer esse comportamento.

Diversos testes laboratoriais podem ser utilizados para observar o desempenho dos materiais adesivos. Atualmente os mais utilizados são os testes de resistência adesiva, dentre eles os testes de tração, cisalhamento, microtração e microcisalhamento. 
Devido à ausência de padronização e à variabilidade nas metodologias empregadas por diferentes centros de pesquisa torna-se difícil a comparação entre os diferentes valores obtidos e reportados na literatura.

Desta forma é necessário investigar se diferentes metodologias podem revelar resultados diferentes para um mesmo material, já que muitas vezes esses estudos são utilizados como indicativos da qualidade e desempenho, influenciando os cirurgiõesdentistas na seleção de materias utilizados na clínica diária. 


\section{REVISÃO DE LITERATURA}

A dentística restauradora adesiva tem causado profundas mudanças na prática odontológica. Técnicas adesivas combinadas com a utilização de materiais restauradores estéticos são frequentemente requeridas pelos pacientes (VAN MEERBEEK et al., 2003). Esse anseio tanto por parte dos pacientes quanto pelos profissionais de Odontologia impulsiona o desenvolvimento de novas técnicas e novos materiais.

Uma das primeiras tentativas de aderir um material resinoso a dentina humana foi realizada por Oskar Hagger (1949) com o composto GPDM (dimetacrilato de glicerolfosfato ácido) que atuava por reação de quelação com o cálcio presente na hidroxiapatita dentinária, mas foi com Buonocore (1955) que efetivamente se deram início as transformações que modificaram as técnicas restauradoras. $\mathrm{O}$ autor observou que a aplicação do ácido fósfórico ao esmalte dental humano poderia aumentar a retenção de resinas acrílicas a este substrato. Tal idéia surgiu de uma técnica que já era utilizada no setor industrial que aplicava ácido fosfórico em superfícies metálicas com o objetivo de melhorar a retenção de tintas a estas superfícies (HENOSTROZA, 2003).

O mecanismo de adesão ao esmalte e à dentina consiste basicamente em um processo de substituição dos minerais removidos dos tecidos dentais duros pelos monômeros resinosos obtendo-se uma retenção micromecânica pela penetração 
desses monômeros nas microretenções criadas com a remoção desses minerais (DE MUNK et al., 2005).

Esta interface criada pelo sistema adesivo e substrato dentinário foi descrita primeiramente por Nakabayashi, Kojima e Masuhara (1982). Esta zona de interdifusão entre a camada de adesivo e a dentina desmineralizada subjacente foi chamada de camada híbrida. De acordo com os autores, a aplicação do ácido fosfórico à dentina promove uma desmineralização superficial expondo uma trama de fibras colágenas que posteriormente seria infiltrada pelo adesivo.

Vários são os fatores que podem alterar a formação e manutenção desta camada híbrida. Estes fatores podem estar vinculados aos dois componentes diretamente envolvidos na hibridização: substrato e sistema adesivo.

Com relação ao substrato podem-se ressaltar as peculiaridades de cada um dos tecidos envolvidos durante a técnica adesiva, o que pode tornar diferente 0 desempenho do mesmo sistema adesivo quando utilizado em diferentes regiões do mesmo elemento dental (SHIMADA; TAGAMI, 2003).

O esmalte dental humano maduro é constituído por $96 \%$ de cristais inorgânicos de hidroxiapatita que constituem a ultraestrutura prismática do tecido, $3 \%$ de água e $1 \%$ de matriz orgânica em peso. É um tecido cristalino altamente mineralizado e de extrema dureza podendo ser modificado por desmineralização ácida (HENOSTROZA, 2003).

A dentina humana é constituída por $18 \%$ de matriz e fibras colágenas, $70 \%$ de cristais de hidroxiapatita e $2 \%$ de água em peso (HENOSTROZA, 2003).

Mashall Jr (1993) ressalta as principais características da dentina humana. Este tecido pode ser considerado como um complexo composto por quatro elementos:(1) túbulos orientados (2) circundados por uma zona peritubular altamente mineralizada 
mergulhado em uma matriz intertubular constituída basicamente de (3) cristais de apatita inseridos em colágeno tipo I e (4) fluido dentinário. A característica estrutural mais marcante da dentina é a presença de túbulos dentinários. Essa natureza tubular é um fator importante para a permeabilidade e umidade do tecido.

Estudos laboratoriais que avaliam a união entre os sistemas adesivos e a dentina comumente utilizam dentes humanos extraídos como substrato. Entretanto com o contínuo aumento da preocupação com a saúde bucal e com uma Odontologia mais conservadora tem havido uma dificuldade na obtenção de dentes humanos hígidos e sem cárie (OESTERLE; SHELLHART; BELANGER, 1998; RUEGGEBERG, 1991; TAGAMI et al., 1989).

Essa dificuldade tem impulsionado a busca por um substrato alternativo para substituir os dentes humanos nos testes de adesão. A dentina bovina tem sido freqüentemente utilizada como alternativa nos estudos in vitro.

Nakamichi, Iwaku e Fusayama (1983) ao observarem a dentina humana e a dentina bovina notaram similaridade entre os dois substratos (figura 2.1). Ao realizarem testes de adesão não encontraram diferença estatística entre eles. Em outro estudo Saunders (1988) não encontrou diferença estatística significante ao comparar os dois substratos utilizando quatro sistemas adesivos distintos. 

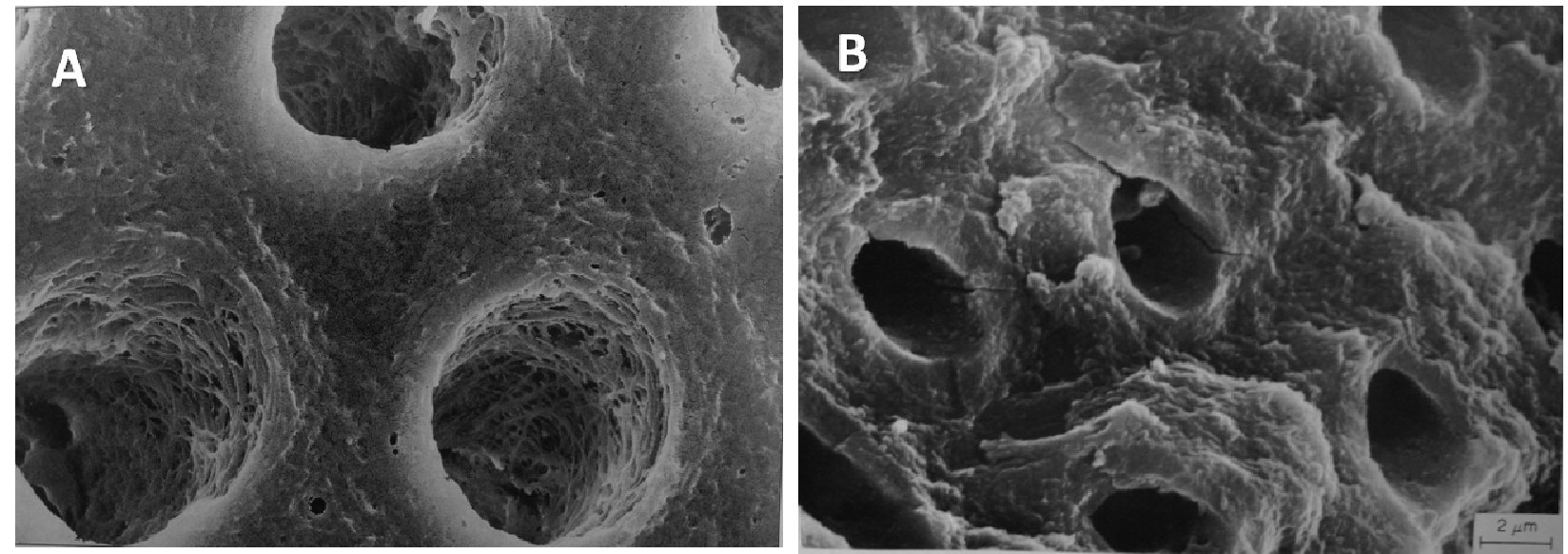

Figura 2.1 - Microscopias eletrônica de varredura da (A) dentina humana com aumento de 12.500x, (B) dentina bovina com aumento de 6000x (adaptado de TAGAMI et al., 1989)

Características anatômicas semelhantes tais como diâmetro, orientação e concentração por unidade de área dos túbulos dentinários também foram descritas na literatura (SAUNDERS, 1988; TAGAMI et al., 1989).

Desta forma os dentes bovinos apresentam-se como uma alternativa confiável aos dentes humanos nos testes laboratoriais de adesão.

Diferenças na composição dos sistemas adesivos também podem ser responsáveis por diferentes formas de interação desses materiais com o substrato dental.

Durante algum tempo os adesivos dentais foram classificados por gerações. Com a profusão de sistemas desenvolvidos essa classificação tornou-se complexa e confusa.

Atualmente os adesivos dentários podem ser classificados de acordo com a estratégia utilizada durante o procedimento adesivo. Os adesivos do tipo condicione e lave utilizam um ácido (mais comumente ácido fosfórico entre 30 e $40 \%$ ) que é aplicado e lavado. Essa etapa de condicionamento é seguida pela aplicação de um 
primer e de uma resina, resultando em um procedimento de três passos de aplicação. Adesivos condicione e lave simplificados que conjugam o primer e a resina adesiva em uma só etapa de aplicação, são denominados adesivos de dois passos (DE MUNCK et al., 2005; VAN MEERBEEK et al., 2003).

O principal inconveniente dessa técnica é a possibilidade de colapso das fibras da matriz de colágeno exposta, na ocorrência de uma secagem excessiva da dentina desmineralizada e a incompleta penetração dos monômeros adesivos (TAY et al., 2005). Essas falhas na camada híbrida podem acarretar a redução da força de união entre material restaurador e elemento dental.

Uma alternativa de abordagem dos sistemas adesivos é baseada na utilização de monômeros ácidos que simultaneamente condicionam e preparam a dentina, sendo denominados adesivos autocondicionantes, podendo ser divididos em um ou dois passos de aplicação (VAN MEERBEEK et al., 2003).

Esses sistemas foram desenvolvidos na tentativa de se criar uma técnica com um menor número de passos clínicos e menos sensível. Nesse sistema a não necessidade da retirada do ácido por meio de lavagem e posterior secagem do substrato exime o operador da decisão a respeito da exata umidade que deve ser mantida sobre a dentina no momento da aplicação do adesivo, não havendo a possibilidade de colapso das fibras colágenas. Com a infiltração do adesivo simultaneamente ao processo de desmineralização da dentina o risco de discrepância entre esses processos é baixo ou inexistente (DE MUNCK et al., 2005).

Outro grupo de pesquisadores propôs uma classificação que se baseia na acidez dos sistemas autocondicionantes. Sistemas com diferentes pHs podem produzir diferentes padrões de condicionamento em esmalte e dentina, por sua diferença de 
acidez e agressividade. Baseado nessas características, os adesivos autocondicionantes podem ser classificados em forte e suave. São considerados fortes os que apresentam um $\mathrm{pH} \leq 1$, produzindo uma desmineralização do esmalte e dentina semelhante ao padrão de condicionamento promovido pelo ácido fosfórico. São denominados suaves aqueles que apresentam $\mathrm{pH} \approx 2$ e não têm a mesma capacidade de desmineralização do ácido fosfórico, alcançando a profundidade de apenas $1 \mu \mathrm{m}$ em dentina (PASHLEY; TAY, 2001; TAY; PASHLEY, 2001).

Recentemente Peumans et al. (2006) sugeriram uma nova classificação com relação à agressividade dos sistemas adesivos autocondicionantes, graças ao surgimento do adesivo Cearfil $\mathrm{S}^{3}$ Bond (Kuraray Co. Ltd) que apresenta $\mathrm{pH} \approx 2,7$. Este adesivo foi classificado como ultra-suave e sua interação com uma espessa camada de esfregaço não resultou em uma camada híbrida autêntica. Após análise por meio de microscopia eletrônica de varredura e microscopia eletrônica de transmissão, os autores observaram que o adesivo não foi capaz de atingir a dentina, promovendo apenas uma hibridização do esfregaço. Mesmo na ausência de esfregaço tal adesivo interagiu minimamente com a dentina formando o que os autores denominaram camada nanohíbrida. Outros estudos têm comparado o desempenho desse adesivo em relação a outros sistemas autocondicionantes.

Reis et al. (2007) analisaram características ultramorfológicas da interface resina-dentina de sistemas adesivos autocondicionante de passo único (Adper Prompt L-Pop, iBond e Clearfil Tri-S Bond) após 24 horas, 60 e 90 dias de sua aplicação. Os resultados mostraram diferentes padrões de nanoinfiltração para os três adesivos testados, sendo que para o adesivo $S^{3}$ foi observada a menor nanoinfiltração após o período de armazenamento de 90 dias. 
Um estudo investigou a relação entre o grau de conversão e a resistência adesiva de sistemas autocondicionantes de passo único (Absolute - Dentsply-Sankin, Clearfil $S^{3}$ Bond - Kuraray, G-Bond - GC, Hybrid Bond - Sun Medical, iBond - Heraeus Kulzer, Xeno IV - Dentsply Caulk, iBond NG - Heraeus Kulzer) aplicados ao esmalte dental humano. Os autores observaram que todos os adesivos testados demonstraram um aumento na resistência adesiva proporcional ao aumento do grau de conversão, sendo que o adesivo Clearfil $S^{3}$ Bond mostrou os maiores valores de adesão imediata (KANEHIRA et al., 2006).

Sadr, Shimada e Tagami (2006) observaram que o adesivo Clearfil SE Bond mostrou maiores valores de resistência adesiva em comparação ao sistema Clearfil $S^{3}$ Bond quando da remoção do solvente e água dos sistemas adesivos autocondicionantes antes da sua polimerização por diferentes tempos de evaporação.

Çelik et al. (2006) avaliaram a resistência adesiva de três sistemas adesivos (Single Bond 2, Clearfil Protect Bond e Clearfil $S^{3}$ Bond) aplicados à dentina preparada com pontas diamantadas e laser de Er:YAG. Observaram que nos grupos convencionalmente preparados não houve diferença significante entre os sistemas Clearfil Protect Bond e Clearfil $S^{3}$ Bond, e que o sistema Single Bond 2 apresentou os menores valores adesão. Já em relação aos grupos preparados com laser somente o sistema Clearfil $S^{3}$ Bond demonstrou um aumento nos valores de resistência adesiva.

Cardoso (2006) estudou o comportamento de sistemas adesivos autocondicionantes frente a técnicas convencionais e alternativas de preparo cavitário. Os sistemas adesivos utilizados foram Optibond FL, Adper Promp L-Pop, Clearfil SE Bond e Clearfil $\mathrm{S}^{3}$ Bond. Como técnicas de preparo cavitário foram utilizados instrumento rotatório convencional, instrumento rotatório CVD, instrumento ultra-sônico 
CVD, laser Er,Cr:YSGG e a dentina fraturada (ausência de camada de esfregaço). Seus resultados reveleram que os adesivos de menor acidez (Clearfil SE Bond e Clearfil $\mathrm{S}^{3}$ Bond) obtiveram melhores resultados quando aplicados em dentina fraturada, concluindo que a camada de esfregaço influenciou de forma negativa o desempenho destes adesivos com relação ä resistência adesiva.

Um aspecto importante a ser observado em relação à acidez dos sistemas adesivos autocondicionantes é a formação das chamadas "water trees ou árvores de água". Tay e Pashley (2003b) demonstraram que existe a formação de um gradiente de concentração entre túbulo dentinário (menos saturado) e superfície de adesivo que permanece em contato com o oxigênio (mais saturado), esta diferença de gradiente de concentração levaria à formação de microscópicos canais preenchidos por água no interior da camada de adesivo. Esta umidade seria resultado da umidade naturalmente presente na dentina ou da água contida na composição do próprio adesivo (VAN LANDUYT et al., 2005).

Estes microcanais de água resultariam em uma camada híbrida que se comportaria como uma membrana semi-permeável (TAY; PASHLEY, 2003a).

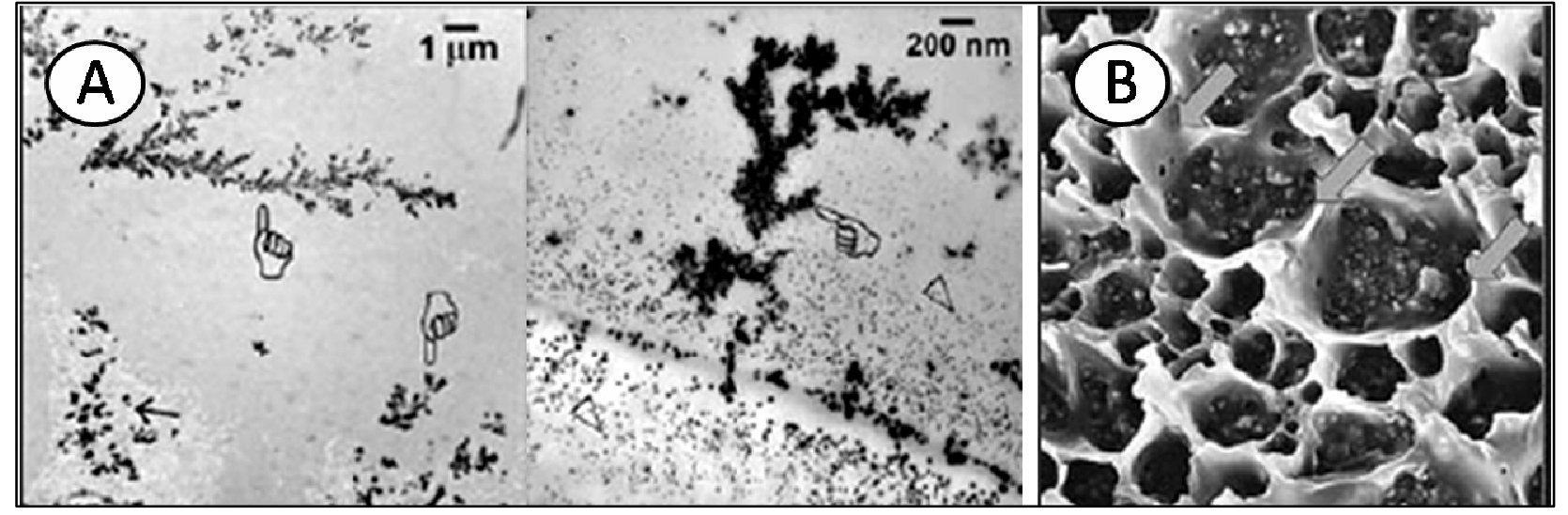

Figura 2.2 - Microscopias eletrônicas de trasmissão evidenciando $(A)$ a formação de árvores de água (water trees) e (B) e a permeabilidade da membrana de adesivo (TAY; PASHLEY,2003a) 
Existem evidências que comprovam que mesmo após a polimerização do adesivo haveria uma movimentação desta água através da espessura da camada de adesivo , este fato acarretaria uma possível "plastificação" da camada híbrida gerando prejuízo da durabilidade desta camada (CHERSONI et al., 2004; TAY et al., 2004; TAY et al., 2005).

Testes laboratoriais são comumente utilizados para avaliar a eficácia de novos materiais restauradores assim como para predizer sua performance clínica (RETIEF, 1991).

Diversas metodologias para avaliar a resistência adesiva têm sido descritos na literatura e a ausência de padronização desses métodos tem sido amplamente discutida.

Muitos fatores podem influenciar nos resultados dos testes, dentre eles o tipo de substrato utilizado, a metodologia empregada, a localização da área a ser testada, o preparo da superfície e a extensão da aplicação do sistema adesivo (DICKENS; MILOS, 2002).

Os parâmetros mais comumente utilizados para essa mensuração são os testes de tração e cisalhamento (DEHOFF; ANUSAVICE; WANG, 1995; MOLL; FRITZENSCHAFT; HALLER, 2004; PASHLEY et al., 1995; TANTBIROJN, et al., 2000). Recentemente, variações desses dois testes têm sido empregadas: o teste de microtração e o teste de microcisalhamento.

A resistência adesiva obtida por testes laboratoriais é denominada resistência nominal ou resistência média. Esse valor é calculado pela divisão da carga necessária para promover a fratura da adesão entre o substrato dental e o material restaurador e a área da secção transversal da interface adesiva (TANTBIROJN et al., 2000; VAN 
NOORT et al., 1989). Como a força de fratura é dada por unidade de área, a dimensão desta área é de extrema importância (PASHLEY et al., 1999).

O teste mecânico de cisalhamento desempenha um importante papel na avaliação da resistência adesiva in vitro. Entretanto há muitas críticas em relação a esse teste devido à grande quantidade de variações e à ausência de padronização entre os diferentes laboratórios variáveis (DICKENS; MILOS, 2002; RETIEF, 1991).

Por outro lado, o teste de cisalhamento continua sendo popular e amplamente utilizado. Essa popularidade pode ser explicada pela relativa simplicidade do teste (SUDSANGIAM; VAN NOORT, 1999; VERSILUIS; TANTBIROJN; DOUGLAS, 1997).

No teste de cisalhamento dois materiais são aderidos por meio de um agente de união e carregados até que ocorra a fratura (VERSILUIS; TANTBIROJN; DOUGLAS, 1997), sendo essa força de carregamento aplicada paralelamente à superfície dental (SUDSANGIAM; VAN NOORT, 1999).

O aperfeiçoamento e a evolução dos sistemas adesivos produziram um aumento nas forças de adesão obtidas em testes laboratoriais e, ao mesmo tempo demonstraram um grande número de falhas coesivas em dentina (ARMSTRONG; KELLER; BOYER, 2001; ØILO; AUSTRHEIM, 1993; PASHLEY et al., 1999). Para evitar fraturas coesivas em dentina durante os testes de adesão seria necesssário melhorar a distribuição do estresse durante o teste.

Sano et al. (1994) com o objetivo de estabelecer se havia alguma relação entre área adesiva e os valores de adesão obtidos descreveu o teste de microtração. Nesse estudo os autores constataram uma relação inversa entre área adesiva e valores de adesão obtidos, ou seja, áreas adesivas menores foram associadas a maiores valores 
de resistência adesiva. Os resultados foram creditados ao fato de espécimes com interfaces adesivas maiores provavelmente possuírem maior quantidade de falhas.

Baseados na teoria de que espécimes com áreas menores aparentemente contém menos defeitos (GRIFFITH, 1920), Shimada, Kikushima e Tagami (2002) desenvolveram o teste de microcisalhamento. Esta metodologia consiste na adesão de cilindros de resina composta com dimensões de $0,8 \mathrm{~mm}$ diâmetro por $0,5 \mathrm{~mm}$ de altura sobre a superfície a ser testada. O teste mecânico de microcisalhamento é realizado com o auxílio de um fio metálico de diâmetro $0,2 \mathrm{~mm}$ que, acoplado à célula de carga da máquina, aplica uma força de afastamento a velocidade de $1 \mathrm{~mm} / \mathrm{min}$ até o momento da fratura.
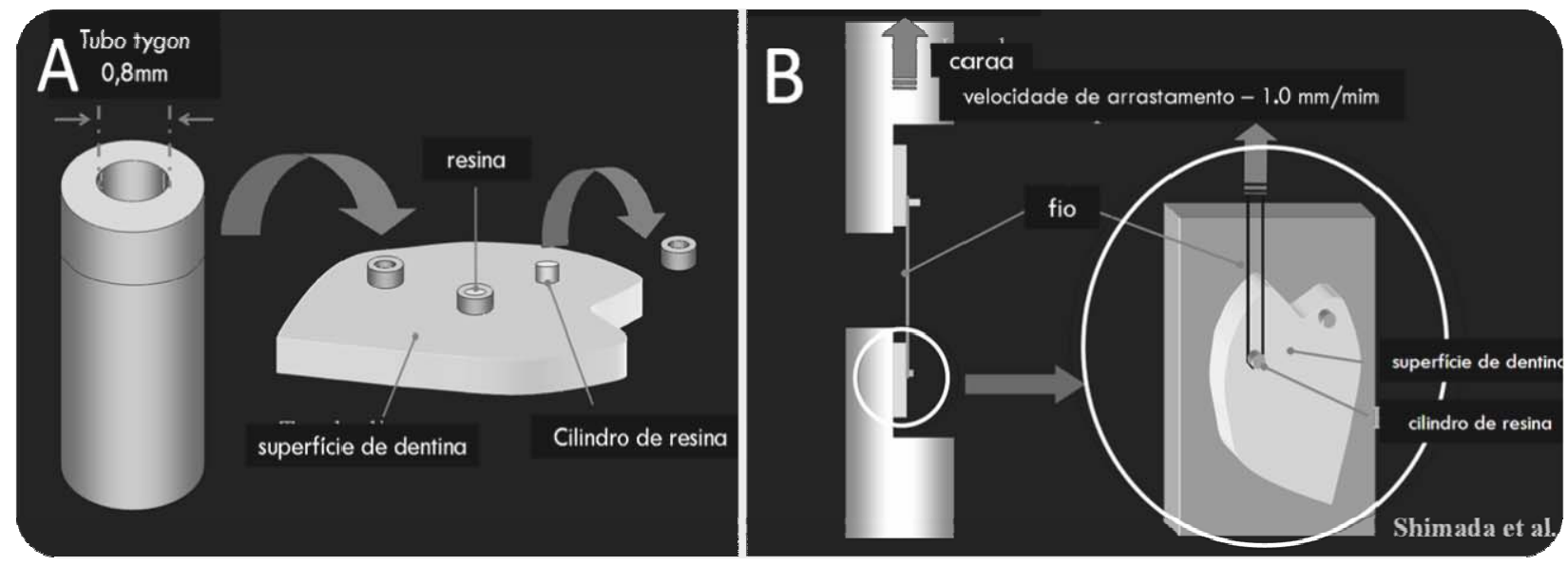

Figura 2.3 - Esquema ilustrativo do ensaio mecânico de microcisalhamento gentilmente cedido pelo Prof.Dr. Junji Tagami.(A) preparo da unidade experimental.(B) amostra submetida à força de cisalhamento

Este teste tem sido utilizado em diversos estudos que objetivam avaliar o desempenho de diferentes sistemas adesivos aplicados a diferentes tecidos dentais 
mineralizados (FOONG et al., 2006; KIKUSHIMA, et al., 2005; MCDONOUGH, et al., 2002; SADR et al., 2007; SADR; SHIMADA; TAGAMI, 2006; SHIMADA; KIKUSHIMA; TAGAMI, 2002).

McDonough et al.(2002), utilizaram o teste de microcisalhamento para avaliar a resistência adesiva de sistemas adesivos autocondicionantes em diferentes regiões de esmalte com diferentes orientações de prismas de esmalte e diferentes profundidades de dentina no mesmo elemento dental e cita como uma das vantagens do teste a possibilidade da utilização de um menor número de dentes para a realização de estudos, a rapidez e facilidade do teste, opinião compartilhada por outros pesquisadores (FOONG et al., 2006; SADR et al., 2007).

Kikushima et al. (2005) compararam o desempenho dos sistemas adesivos Clearfil SE Bond e Single Bond quando aplicados à dentina e ao cemento dental. A resistência de união destes sistemas adesivos também foi mensurada por meio do teste de microcisalhamento. Concluíram que as maiores resistências adesivas foram obtidas em dentina independentemente do sistema adesivo utilizado.

Muitos pesquisadores tratam e aplicam os sistemas adesivos sobre toda a superfície dentinária ao realizarem ensaios mecânicos convencionais de resistência adesiva, enquanto outros restringem o tratamento apenas a uma área demarcada (CHIBA et al., 2006; KANEHIRA et al., 2006; KIKUSHIMA et al., 2005; NAKABAYASHI; KOJIMA; MASUHARA, 1982; ; TANTBIROJN et al., 2000; VAN NOORT et al., 1991); Já no ensaio mecânico de microcisalhamento apesar do posicionamento do tubo tygon não há a delimitação da área adesiva (SADR, et al., 2007; SADR; SHIMADA; TAGAMI, 2006; SHIMADA; KIKUSHIMA; TAGAMI, 2002). 
Van Noort et al. (1991) ao estudarem o efeito da delimitação da área adesiva concluíram que a extensão do adesivo além da interface adesiva resultaria em valores artificiais de resistência adesiva.

Diferentes variáveis podem interferir nos valores obtidos, como por exemplo, substrato, procedimento adesivo, operador, armazenamento dos espécimes e a metodologia empregada (FOWLER et al., 1992).

Foong et al. (2006) estudaram se uma variação na metodologia do teste de microcisalhamento poderia interferir nos resultados obtidos. Ao avaliarem quatro sistemas adesivos (Clearfil Protect Bond, Xeno III, G Bond, One-Up Bond), realizaram o a força de cisalhamento com auxílio de lâmina e fio. Os autores comprovaram que alterações na metodologia podem afetar os resultados de resistência de união obtidos.

Nota-se que diferentes materiais adesivos, assim como diferenças na distribuição do stress na interface adesiva podem causar diferentes modos de fratura (PASHLEY et al., 1995), portanto diferentes testes laboratoriais podem apresentar diferenças em relação aos modos de fratura (WATANABE; NAKABAYASHI, 1994).

Alguns autores (ARMSTRONG; KELLER; BOYER, 2001; PHRUKKANON, BURROW, TYAS, 1998) têm utilizado o tipo de fratura ocorrido nos espécimes para avaliar os testes laboratoriais de adesão e também tentado correlacionar o tipo de fratura ocorrido nos espécimes com os valores de resistência adesiva obtidos.

A discrepância nos valores de adesão reportados por diferentes centros de pesquisa tem sido atribuída há diferenças nas técnicas de mensuração (VAN NOORT et al., 1991). Desta forma torna-se difícil a comparação entre os diferentes valores obtidos e reportados na literatura. 
Depois de lida a revista de literatura selecionada para este estudo, a presença de divergências geraram alguns questionamentos que estimularam a realização desta pesquisa. 


\section{PROPOSIÇÃo}

Este estudo tem como objetivos:

3.1 Avaliar se, no ensaio mecânico de microcisalhamento, a delimitação da área adesiva a ser testada é capaz de alterar os resultados de resistência de união obtidos.

3.2 Determinar se a delimitação da área adesiva do ensaio mecânico de microcisalhamento pode alterar o ranqueamento dos sistemas adesivos analisados.

3.3 Correlacionar os tipos de fratura encontrados com a modificação de metodologia proposta. 


\section{MATERIAIS E MÉTODO}

Neste capítulo serão listados todos os materiais, instrumentais e equipamentos utilizados para a realização desse estudo, assim como descritos o delineamento experimental e os procedimentos executados para a resposta dos questionamentos científicos apresentados no capítulo anterior.

\subsection{Materiais, instrumental e equipamentos}

18 incisivos bovinos

Ácido fosfórico 35\% (3M ESPE, St. Paul, Minn, USA)

Adesivo à base de cianoacrilato (Loctite 454, Henkel Loctite Corp., Rocky Hill, CT, USA) Adper $^{\text {TM }}$ Single Bond 2 (3M ESPE, St. Paul, Minn, USA - lote 5CW, validade 2008-05) Água destilada

Bisturi descartavel $n^{\circ} 15$ - lâmina inox (Embramed, Jurubatuba, SP, BR)

Clearfil S ${ }^{3}$ Bond (Kuraray.Co, Osaka, Japan - lote 41125, validade 2008-05)

Clearfil SE Bond (Kuraray.Co, Osaka, Japan - lote 51377, validade 2008-05)

Cortadeira metalográfica (Labcut modelo 1010, Extec, Enfield, CT, USA)

Disco de lixa de granulação 120 e 600 (Extec, Enfield, CT, USA)

Disco diamantado (Extec, Enfield, CT, USA) 
Estufa para cultura bacteriológica (Orion 502, Fanem, Guarulhos, SP, BR)

Fio ortodôntico de aço inox. para amarrilho $\varnothing 0.20 \mathrm{~mm}$ ou $\varnothing$.008" (Morelli Ortodontia, Sorocaba, BR)

Fita dupla-face de polipropileno 0,05 mm de espessura (Tectape, Manaus AM, BR) Fotopolimerizador de luz halógena (Jetlite 4000 Plus, J. Morita USA Inc., CA, USA) Gotejador PKT 1 Duplo Guth

Lixadeira (Politriz Ecomet 6 Automet-Buehler, Lake Buff, IL, USA - FAPESP 2003/12182-4)

Lupa estereoscópica com lente de aumento 40x (SZ40 - Olympus Corporation,Tokio, Japan)

Máquina universal de ensaios de materiais (Mini Instron 4442, Canton, MA, USA)

Microscópio eletrônico de varredura (LEO 430i, LEO Electron Microscopy, Cambridge, UK)

Paquímetro digital (série 500, Mitutoyo Sul Americana, São Paulo, SP, BR)

Perfurador de lençol de borracha (modelo Ainsworth, Wilcos do Brasil Indústria e Comércio Ltda, Petrópolis, RJ, BR).

Pinça Adson sem dente 12cm (Erwin Guth, São Paulo, SP, BR)

Pinça anatomica $30 \mathrm{~cm}$ (Erwin Guth, São Paulo, SP, BR)

Pincéis descartáveis Brush M (3M ESPE, St. Paul, Minn, USA)

Recipientes plásticos $10 \mathrm{~mL}$ (Injeplast, São Paulo, SP, BR)

Resina composta Z100 (3M ESPE, St. Paul, Minn, USA)

Seringa tríplice (Dabi Atlante, Ribeirão Preto, BR)

Aplicativo para bioestatistica GMC 8.1 (www.forp.usp.br/restauradora/gmc/gmc.html) Sputter coater SDC 050 (Bal-tec, AG,Liechtenstein) 
Stubs de alumínio para microscópio eletrônico de varredura

Tubos plásticos com diâmetro interno de 1,0 mm (Tygon, Norton Performance Plastic Co, Cleveland, OH, USA)

\subsection{Método}

\subsection{1 delineamento experimental}

Neste estudo a variável de resposta, resistência adesiva, foi avaliada quantitativamente por meio do ensaio mecânico de microscisalhamento. Os fatores de variação foram a delimitação da área adesiva, em 2 níveis (com e sem delimitação da área adesiva), e o sistema adesivo utilizado, em 3 níveis (Adper Single Bond 2, Clearfil Se Bond, Clearfil $S^{3}$ Bond), totalizando 6 níveis de variação.

As unidades experimentais foram confeccionadas sobre 18 superfícies de dentina obtidas a partir de incisivos bovinos, totalizando um $n=12$. 


\subsection{2 seleção e preparo das amostras}

Foram selecionados 18 incisivos bovinos que possuíam curvatura vestibular (cérvico-incisal e mésio-distal) menos acentuada. Os dentes tiveram suas superfícies palatinas desgastadas em lixadeira com lixas de granulação 120 , sob refrigeração, para a exposição da câmara pulpar e obtenção de uma superfície plana. As superfícies vestibulares foram desgastadas paralelamente às superfícies palatinas para a obtenção de superfícies planas em dentina. O desgaste vestibular foi realizado até que se atingisse uma espessura de aproximadamente $3 \mathrm{~mm}$ de dentina. Esta espessura foi verificada com paquímetro digital.

Foram então realizados dois cortes transversais com disco diamantado em cortadeira metalográfica sob refrigeração. O primeiro na junção amelo-cemento para a remoção das raízes e segundo no terço incisal, obtendo-se fragmentos de dentina de aproximadamente $5 \mathrm{~mm}$ de comprimento.

Após a obtenção dos fragmentos realizou-se a padronização da camada de esfregaço da superfície dentinária com lixas de granulação 600 em lixadeira durante 1 minuto (CHIBA et al., 2006; KIKUSHIMA et al., 2005; SADR et al., 2007; SADR; SHIMADA; TAGAMI, 2006).

A seguir os 18 fragmentos foram distribuídos aleatoriamente em 3 grupos, segundo o sistema adesivo a ser utilizado. 


\subsection{3 confecção das unidades experimentais}

Os fragmentos dentais foram imaginariamente divididos ao meio, seguindo seu eixo longitudinal. As superfícies mésio-vestibulares foram destinadas à confecção dos corpos de prova com delimitação da área adesiva e as superfícies disto-vestibulares à confecção dos corpos de prova sem delimitação da área adesiva. Desta forma foram compostos 6 grupos experimentais segundo os dois fatores de variação a serem estudados: sistema adesivo e delimitação da área adesiva (Figura 4.1).

Sobre cada superfície dentinária foram confeccionados 4 cilindros em resina composta, sendo 2 com delimitação da área adesiva e 2 sem a delimitação desta área, totalizando $n=12$. 


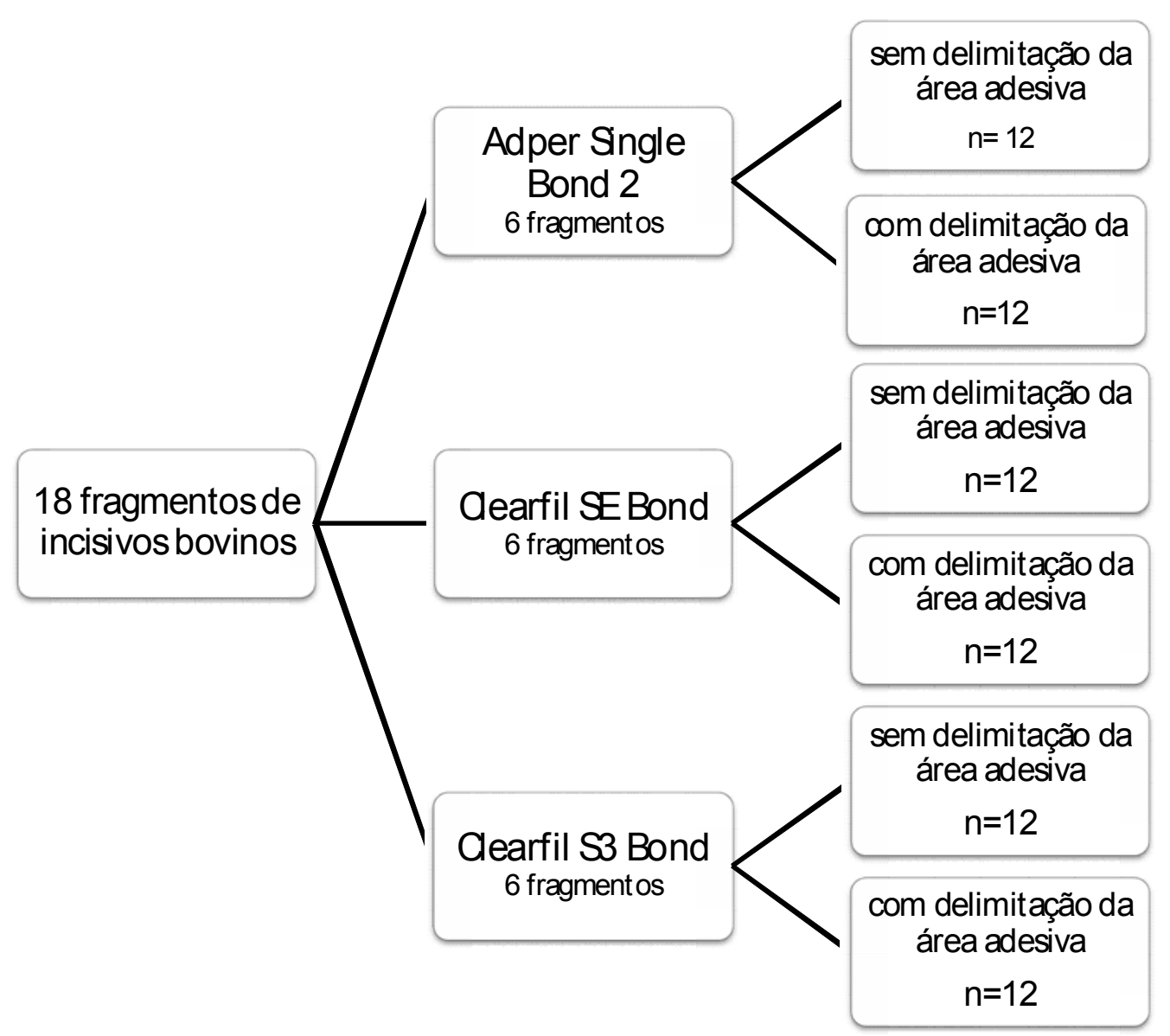

Figura 4.1 - Esquema de formação dos grupos experimentais segundo os fatores de variação

A delimitação da área adesiva foi realizada com fita adesiva dupla face ácido resistente. Foram recortados fragmentos de fita de dimensões suficientes para recobrir metade da superfície de cada amostra. Cada fragmento de fita recebeu duas perfurações circulares alinhadas, com $1,0 \mathrm{~mm}$ de diâmetro realizadas com um perfurador de lençol de borracha.

Uma face adesiva da fita foi aderida ao fragmento, delimitando duas superfícies de dentina com diâmetro de $1,0 \mathrm{~mm}$, sobre as quais foram aplicados os sistemas adesivos de acordo com as instruções dos respectivos fabricantes (Quadro 4.1). 


\begin{tabular}{|c|c|c|}
\hline $\begin{array}{l}\text { SISTEMA ADESIVO } \\
\text { (FABRICANTE) }\end{array}$ & COMPOSIÇÃO QUÍMICA & PROTOCOLO DE APLICAÇÃO \\
\hline $\begin{array}{c}\text { Adper Single Bond } 2 \\
\text { (3M ESPE) }\end{array}$ & $\begin{array}{l}\text { Bis-GMA, HEMA, diuretano dimetacrilato, } \\
\text { copolímero do ácido polialcenóico, } \\
\text { canforoquinona, água, etanol e glicerol } \\
1.3 \text { dimetacrilato, } 10 \% \text { em peso de } \\
\text { nanopartículas de sílica }(5 \mathrm{~nm}) \text {. }\end{array}$ & $\begin{array}{l}\text { Condicionamento da dentina com } \mathrm{H} 3 \mathrm{PO} 435 \% \text { por } 10 \mathrm{~s} \text {; } \\
\text { lavagem por } 10 \mathrm{~s} \text {; secagem com leve jato de ar; aplicar } 2 \\
\text { camadas consecutivas de adesivo com pincel saturado de } \\
\text { material agitando-o gentilmente na superfície por } 15 \\
\text { segundos. Secar gentilmente para evaporar o solvente. } \\
\text { Fotopolimerizar por } 10 \mathrm{~s} \text {. }\end{array}$ \\
\hline $\begin{array}{l}\text { Clearfil SE Bond } \\
\text { (Kuraray Co. Ltd.) }\end{array}$ & $\begin{array}{l}\text { Primer: 10-MDP; HEMA; dimetacrilato } \\
\text { hidrofílico; canforquinona; amina terciária } \\
\text { aromática; } \mathrm{H}_{2} \mathrm{O} \\
\text { Bond: } 10-\mathrm{MDP} \text {; Bis-GMA; HEMA; } \\
\text { dimetacrilato hidrofóbico; canforquinona; } \\
\text { amina terciária aromática; sílica coloidal } \\
\text { silanizada }\end{array}$ & $\begin{array}{l}\text { Aplicar o primer por } 20 \mathrm{~s} \text {; secar com leve jato de ar; aplicar o } \\
\text { Bond; aplicar leve jato de ar; fotopolimerizar por } 10 \mathrm{~s} \text {. }\end{array}$ \\
\hline $\begin{array}{l}\text { Clearfil S }{ }^{3} \text { Bond } \\
\text { (Kuraray Co. Ltd.) }\end{array}$ & $\begin{array}{l}\text { 10-MDP; Bis-GMA; HEMA; dimetacrilato } \\
\text { hidrofóbico; canforquinona; etanol; } \mathrm{H}_{2} \mathrm{O} \text {; } \\
\text { sílica coloidal silanizada }\end{array}$ & $\begin{array}{l}\text { Aplicar o adesivo por } 20 \mathrm{~s} \text {; secar com forte jato de ar por mais } \\
\text { que } 5 \mathrm{~s} \text { para afinar a camada de adesivo; fotopolimerizar por } \\
\text { 10s. }\end{array}$ \\
\hline
\end{tabular}

Quadro 4.1 -Composição química e protocolo de aplicação segundo seus respectivos fabricantes dos sistemas adesivos utilizados

À outra face da fita foi posicionado um tubo tygon com diâmetro interno de 1,0 $\mathrm{mm}$ e altura de $0,5 \mathrm{~mm}$ de forma que seu diâmetro interno coincidisse com a perfuração da fita. Após o posicionamento dos tubos o sistema adesivo utilizado era fotopolimerizado.

A seguir foram realizados os procedimentos adesivos sobre a hemi-superfície dentinária sem a delimitação da área adesiva. Previamente à fotopolimerização dos 
sistemas adesivos foram posicionados dois tubos plásticos tygon contra lateralmente aos posicionados anteriormente.

A seguir os tubos foram preenchidos com resina composta microhíbrida que foi fotopolimerizada por 40 segundos.

Os espécimes foram armazenados em água destilada à temperatura de $37^{\circ} \mathrm{C}$. Decorrida 1 hora de armazenamento os tubos foram cortados em hemi-círculos e removidos com o auxílio de uma lâmina de bisturi. Os corpos de prova foram observados por meio de lupa esterioscópica com 40 x de aumento para certificação da ausência de defeitos.

Após 24 horas de armazenamento os espécimes foram submetidos ao ensaio mecânico de microcisalhamento. 

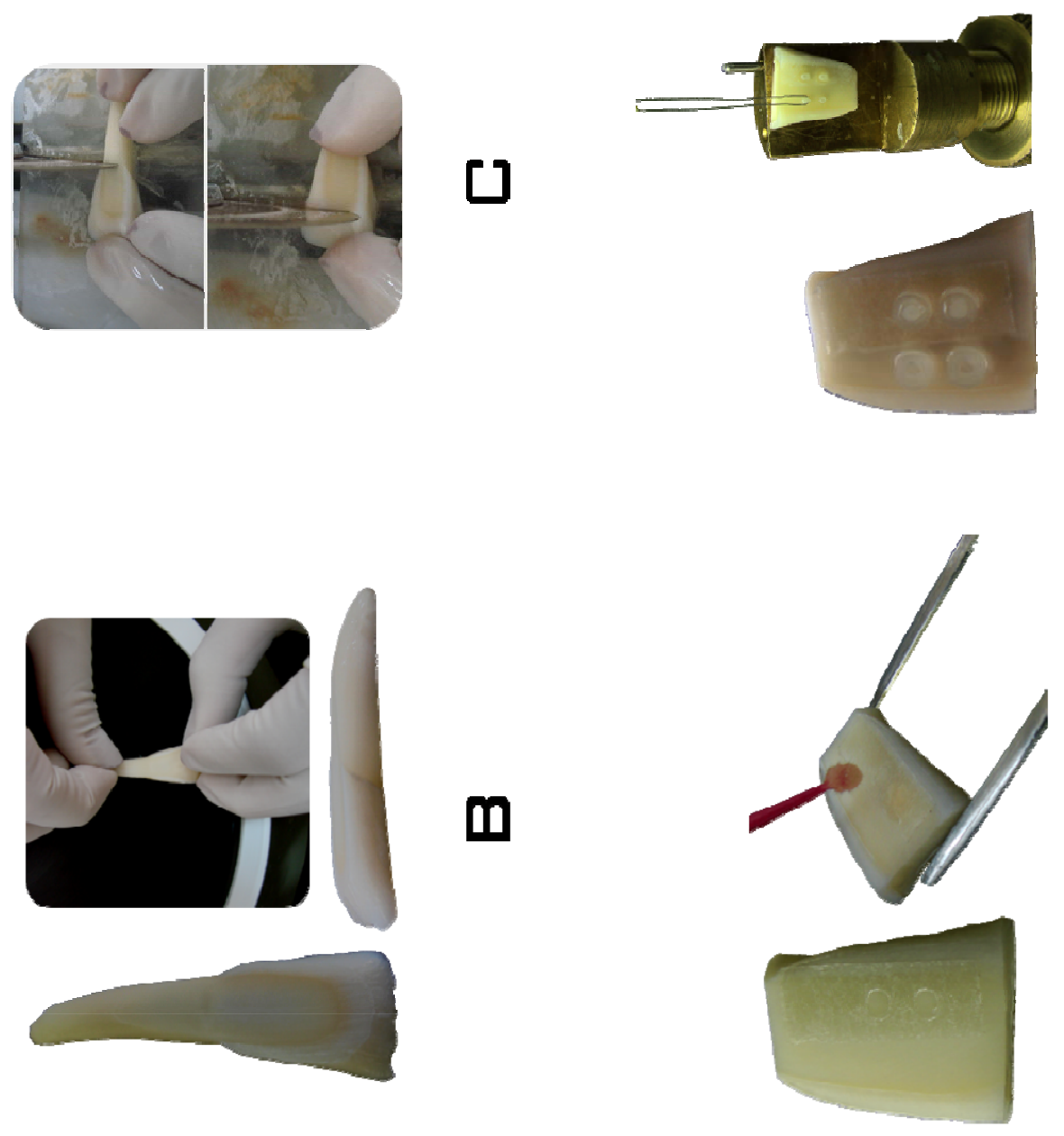

m
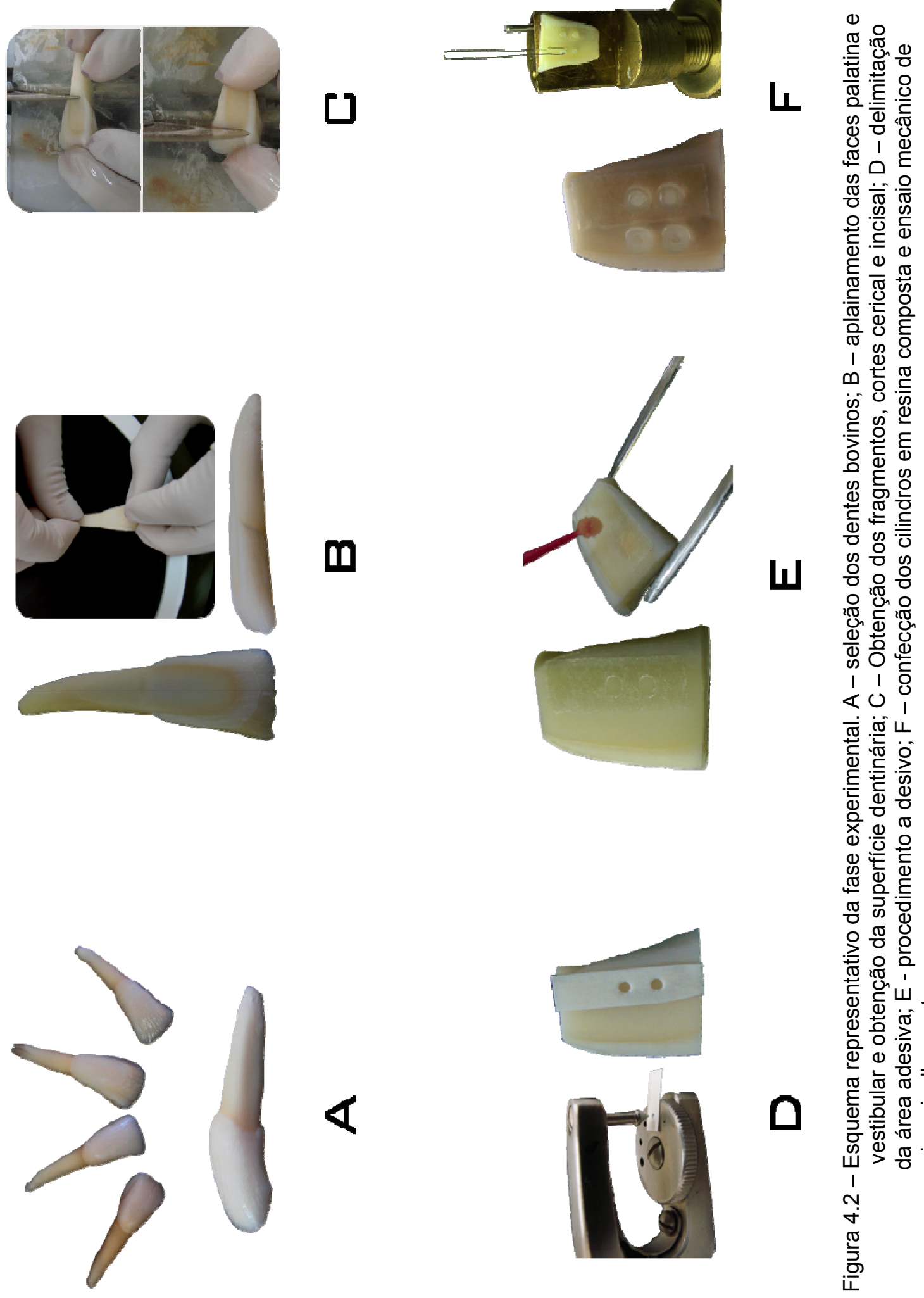

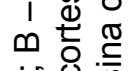
के 0 क 을 ชั ญ ฮ क 등 응 造蛋 응

ل1 $\quad 000$ i⿱宀 ख్ల్ कㅇํㄴ \begin{tabular}{lll}
1 & 1 & 0 \\
\hline & 0 & 0
\end{tabular} तं

苋

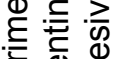

屯 ช. (1) 은 운 D 苋 윽 तु के क्ष 융 은 존 웜山 웅 के 흥 응 $\frac{\text { क }}{0}$ ब0 0 。

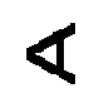

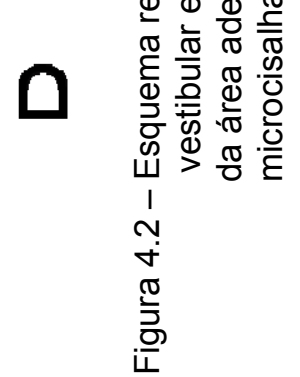




\subsection{4 ensaio mecânico de microcisalhamento}

O ensaio mecânico de microcisalhamento foi realizado conforme descrito por Shimada, Kikushima e Tagami (2002).

Os fragmentos dentais foram fixados ao dispositivo da máquina universal de testes de materiais com adesivo à base de cianocrilato de modo que os cilindros de resina composta permanecessem alinhados da célula de carga.

Um fio metálico de $0,2 \mathrm{~mm}$ de diâmetro laçava o prolongamento da célula de carga da máquina e simultaneamente cada cilindro de resina composta. O fio mantinha contato com o semicírculo inferior dos cilindros, mantendo contato com a superfície dentinária.

A força de cisalhamento foi aplicada a uma velocidade de $1 \mathrm{~mm} / \mathrm{min}$ até que ocorresse a fratura do espécime. Os valores no momento da fratura foram registrados em Newton e posteriormente convertidos para MegaPascal segundo a fórmula:

$$
\mathrm{MPa}=\frac{\text { Newton }}{\text { área }\left(\mathrm{mm}^{2}\right)}
$$

4.2.5 análise dos padrões de fratura

Após o teste de microcisalhamento o padrão de fratura de cada amostra foi determinado com o auxílio de lupa esteroscópica, com aumento de 40x. 
As fraturas foram classificadas como adesivas (falhas interfaciais entre substrato e adesivo), coesivas em dentina, coesivas em resina (falhas na resina composta ou na camada de adesivo) e mistas (mais de um dos tipos citados).

\subsection{6 tratamento estatístico dos dados}

Os dados foram primeiramente analisados quanto à normalidade na distribuição dos erros amostrais e quanto á homogeneidade das variâncias por meio dos testes de aderência à curva normal e Cochran respectivamente.

A distribuição amostral analisada foi considerada normal e homogênea. Desta forma utilizou-se o teste estatístico paramétrico ANOVA para dois fatores de variação e o teste auxiliar de Tukey para que possíveis diferenças estatísticas significantes fossem detectadas entre os grupos testados, considerando-se um nível de significância de $1 \%$ $(p<0,01)$.

4.2.7 microscopia eletrônica de varredura

Além da análise do padrão de fratura ter sido realizada em microscópio esterescópico, duas amostras de cada grupo foram processadas para análise em microscópio eletrônico de varredura. 
Após as fraturas os fragmentos dentais foram armazenados secos por um período não superior a 24 horas e fixados em stubs de alumínio. Em seguida, todos os espécimes receberam cobertura de ouro e foram observados em microscópio eletrônico de varredura. 


\section{RESULTADOS}

\subsection{Resistência adesiva}

Os resultados dos testes de aderência à curva normal, do teste ANOVA para dois fatores de variação e teste auxiliar de Tukey estão dispostos nas tabelas 5.1, 5.2 e 5.3.

Tabela 5.1 - Teste de aderência à curva de normalidade

FREQÜÊNCIAS POR INTERVALOS DE CLASSE

\begin{tabular}{lcccccccc}
\hline Intervalos de classe & M-3s & M-2s & M-1s & Med. & M+1s & M+2s & M+3s \\
Curva normal & 0.44 & 5.40 & 24.20 & 39.89 & 24.20 & 5.40 & 0.44 & 0.00 \\
Curva experimental & 1.39 & 5.56 & 16.67 & 44.44 & 23.61 & 8.33 & \\
\end{tabular}

CÁLCULO DO QUI QUADRADO

Graus de liberdade

4

Valor do Qui quadrado

4.48

Probabilidade de Ho
Interpretaçäo

A distribuiçäo amostral testada é normal 
Tabela 5.2 - Resultado do teste ANOVA para dois fatores de variação

\begin{tabular}{cccccc}
\hline $\begin{array}{c}\text { Fonte de } \\
\text { Variação }\end{array}$ & $\begin{array}{c}\text { Soma de } \\
\text { quadrados }\end{array}$ & G.L. & Quadrados médios & (F) & Probabilidade de H0 \\
Entre colunas & 235.5577 & 1 & 235.5577 & 17.44 & $\mathbf{0 . 0 2 4 \%}$ \\
Entre linhas & 714.3242 & 2 & 357.1621 & 26.45 & $\mathbf{0 . 0 0 0 \%}$ \\
Interação C x L & 1221.1428 & 2 & 610.5714 & 45.22 & $\mathbf{0 . 0 0 0 \%}$ \\
Resíduo & 891.2330 & 66 & 13.5035 & & \\
Variação total & 3062.2578 & 71 & & & \\
\hline
\end{tabular}

Tabela 5.3 - Resultado do teste de Tukey $(p<0,01)$

Resíduo na análise de variância

13.5034

Nível de probabilidade indicado 1

Número de dados da amostra

72

Número de médias comparadas

6

Número de dados para cada média 12

Graus de liberdade do resíduo 66

Valor de q tabelado, (ao nível de 1\%), 4.978 para 6 médias e 66 graus de liberdade

Valor crítico de Tukey calculado 5.28065 
Os valores obtidos com ensaio mecânico de microcisalhamento para os diferentes grupos experimentais estão apresentados no anexo A.

A tabela 5.4 apresenta as médias de resistência adesiva (em MPa) dos grupos e seus respectivos desvios-padrão.

Tabela 5.4 - Resultados do teste de microcisalhamento por grupo experimental

\begin{tabular}{ccc}
\hline Sistema Adesivo & Área adesiva & $\begin{array}{c}\text { Média em Mpa } \\
\text { (Desvio-padrão) }\end{array}$ \\
\hline Adper Single Bond 2 & sem delimitação & $24,83(1,87)$ \\
& com delimitação & $15,24(3,16)$ \\
\hline Clearfil SE Bond & sem delimitação & $24,40(3,56)$ \\
& com delimitação & $14,94(3,49)$ \\
\hline \multirow{2}{*}{ Clearfil S ${ }^{3}$ Bond } & sem delimitação & $30,16(4,61)$ \\
& com delimitação & $19,43(4,61)$ \\
\hline
\end{tabular}

Quando o fator de variação delimitação da área adesiva foi analisado, independentemente do sistema adesivo utilizado, a análise estatística mostrou que todos os grupos experimentais em que essa delimitação foi realizada apresentaram menores valores de resistência adesiva quando comparados aos seus respectivos grupos controle (sem delimitação da área adesiva).

Considerando-se o fator de variação sistema adesivo quando da delimitação da área adesiva não foram observadas diferenças estatisticamente significantes entre os adesivos empregados. Em contrapartida, quando não foi realizada a delimitação, o sistema adesivo Clearfil $S^{3}$ Bond mostrou maiores valores de resistência adesiva quando comparado aos sistemas Adper Single Bond 2 e Clearfil SE Bond, que por sua vez não se mostraram estatisticamente diferentes entre si. 
O Gráfico 5.1 mostra uma representação esquemática dos resultados obtidos no teste de resistência adesiva ao microcisalhamento.

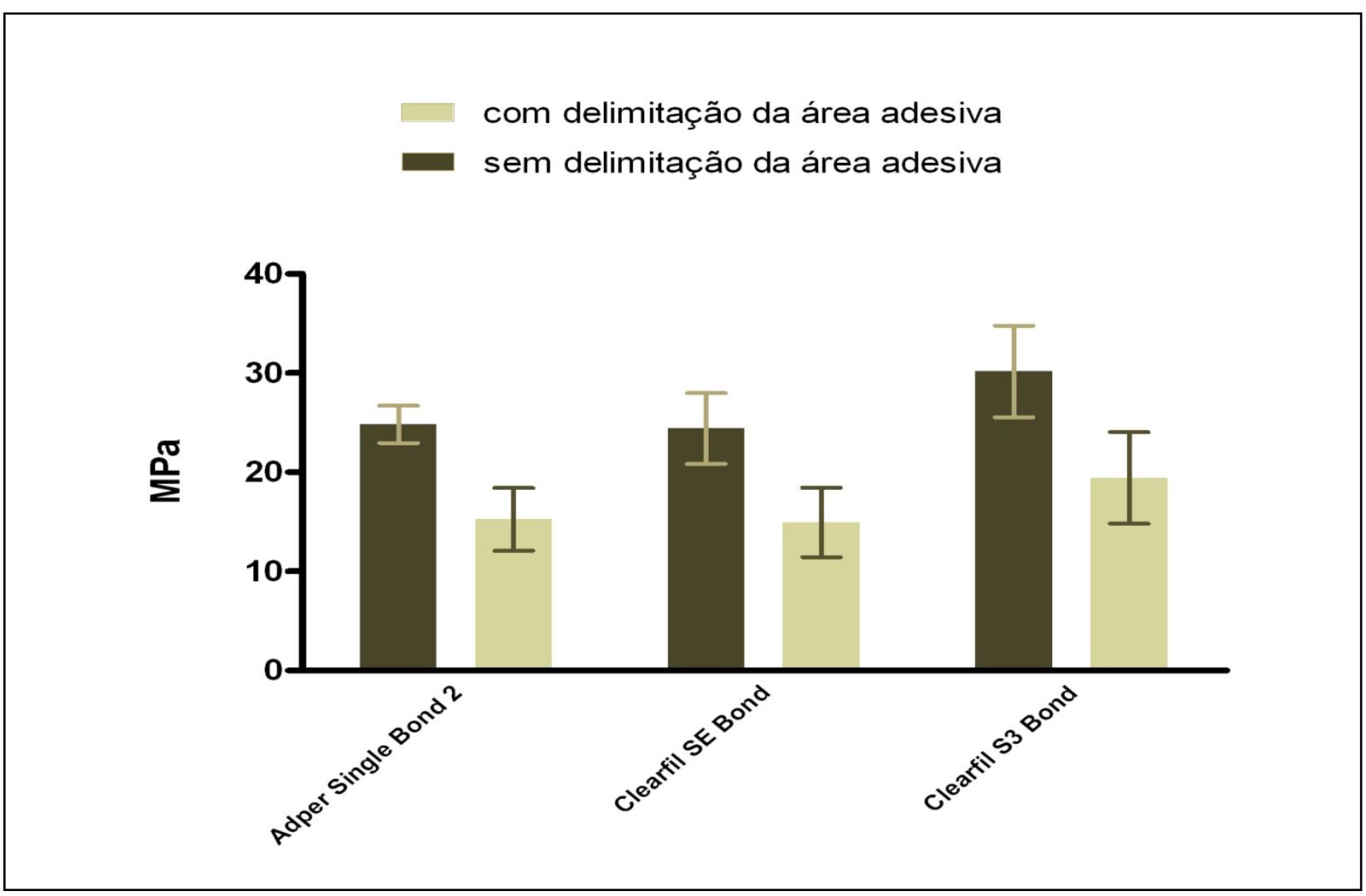

Gráfico 5.1 - Valores médios e desvios-padrão dos grupos experimentais

\subsection{Análise de fraturas}

Os resultados da análise do padrão de fratura dos espécimes em cada em dos grupos experimentais está representado nos gráficos 5.2 e 5.3 .

Não houve ocorrência de falha pré-teste em nenhum dos grupos experimentais.

Houve uma predominância de fraturas do tipo mista em todos os grupos experimentais estudados, à exceção do grupo em que o sistema adesivo utilizado foi o 
Adper Single Bond 2 e a delimitação da área foi realizada, verificando-se quantidades semelhantes de fraturas do tipo adesiva e mista.

Fraturas do tipo coesiva em dentina foram encontradas somente nos grupos em que a delimitação da área adesiva não foi realizada. Em contrapartida, fraturas do tipo adesivas estão predominantemente presentes nos grupos em que essa delimitação foi realizada, com exceção do grupo em que se aplicou o sistema Adper Single Bond 2 (Gráfico 5.2).

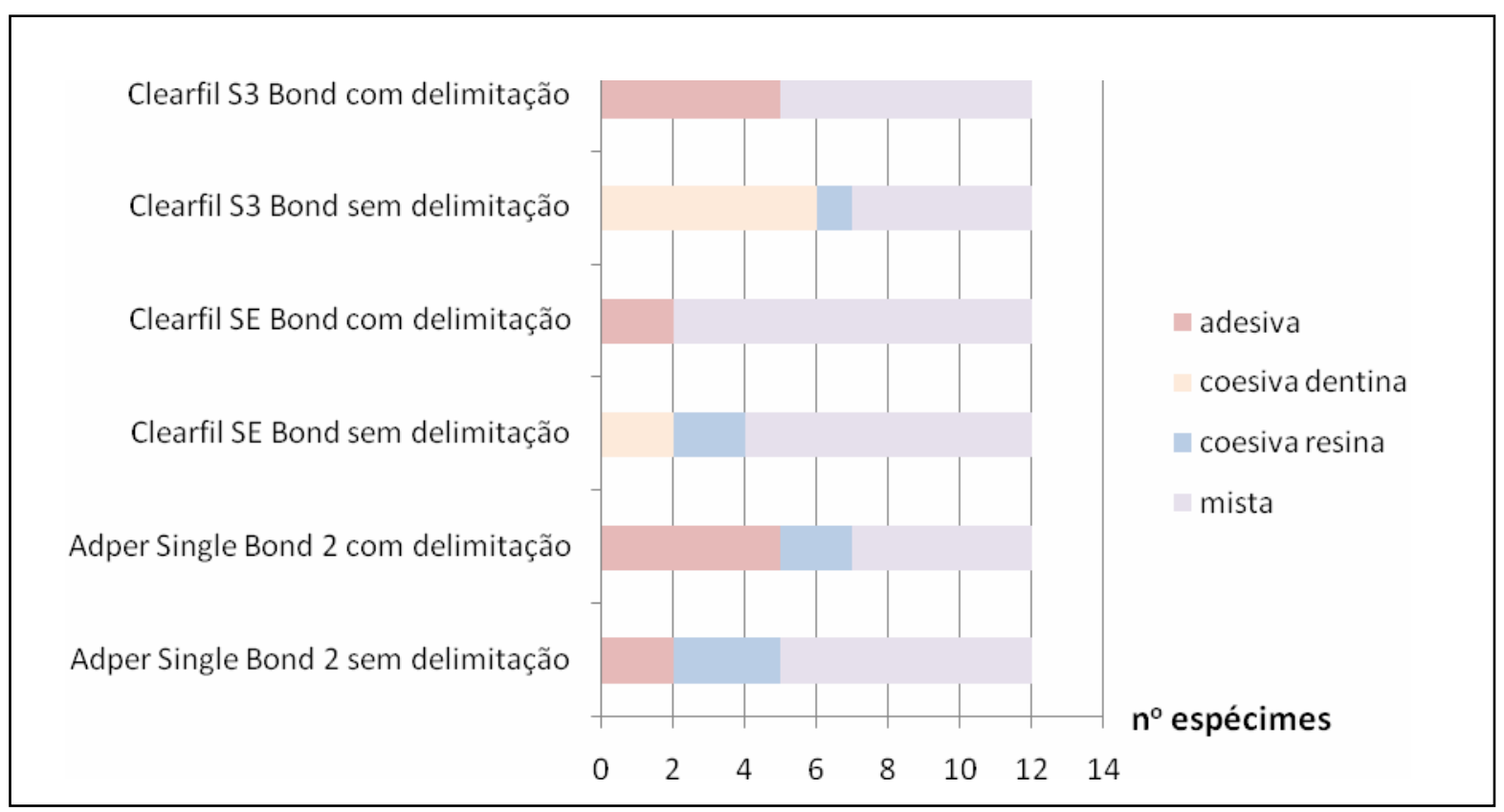

Gráfico 5.2 - Análise do padrão de fratura após realização do teste de microcisalhamento conforme as variáveis estudadas

Ao se analisar os tipos de fratura, independentemente da delimitação da área adesiva e dos sistemas adesivos utilizados, nota-se uma maior ocorrência de fraturas mistas seguidas pelas fraturas adesivas e finalmente pelas fraturas coesivas (Gráfico $5.3)$. 
Analisando-se apenas o fator de variação delimitação da área adesiva, nota-se uma maior incidência de fraturas coesivas quando a delimitação não foi realizada (Gráfico 5.4).

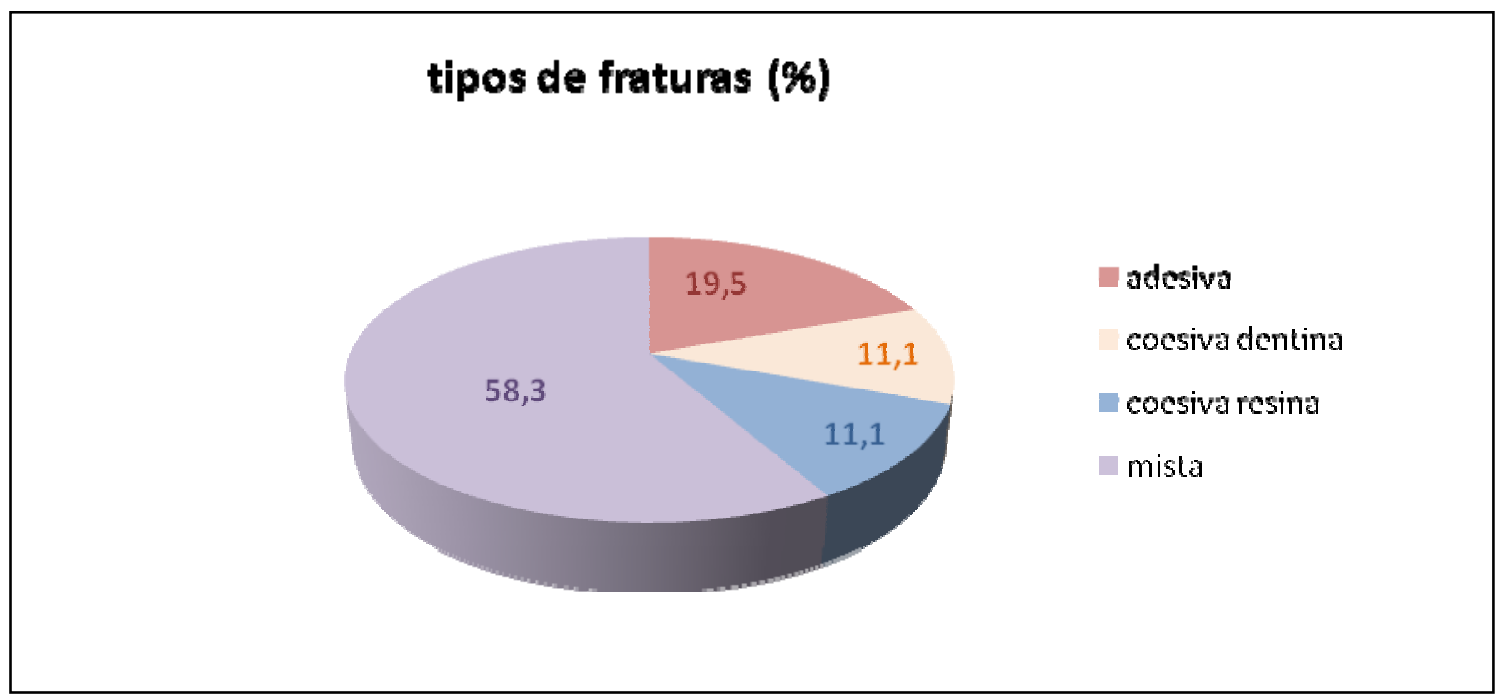

Gráfico 5.3 - Distribuição dos tipos de fratura no teste de microcisalhamento

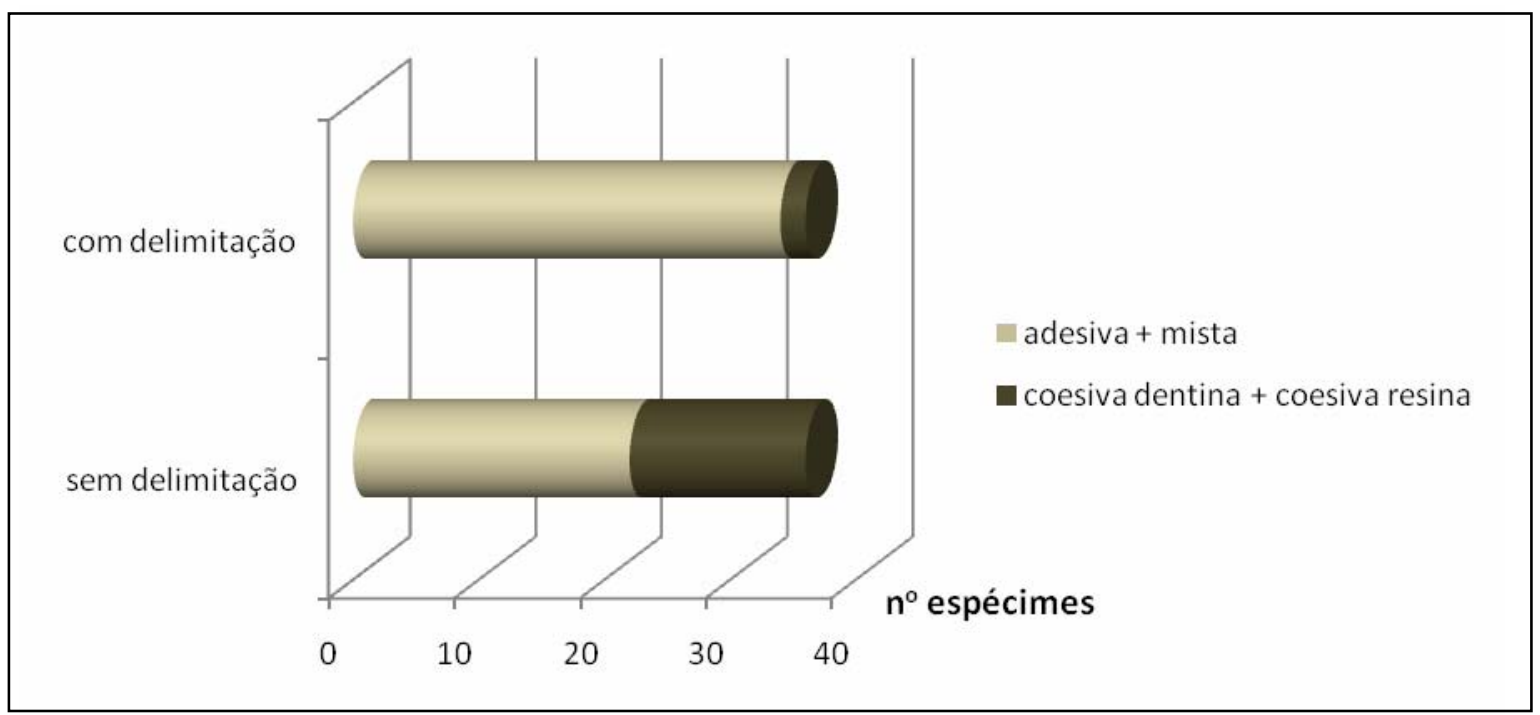

Gráfico 5.4 - Distribuição dos tipos de fratura no teste de microcisalhamento segundo o fator de variação delimitação da área adesiva 


\section{DISCUSSÃO}

A Dentística restauradora estética e a filosofia de tratamento restaurador minimamente invasivo têm sido baseadas no conceito da adesão dos materiais restauradores aos tecidos dentais mineralizados. Desta forma os sistemas adesivos desempenham um papel fundamental na Odontologia atual.

Os testes laboratoriais são amplamente utilizados para a avaliação desses materiais por apresentarem algumas vantagens em relação aos estudos clínicos. Dentre essas vantagens pode-se ressaltar a possibilidade de se estudar isoladamente as diversas variáveis que poderiam interferir no desempenho dos materiais, o menor tempo e custo despendidos para a realização da pesquisa (DE MUNCK, et al., 2005; SUDSANGIAM; VAN NOORT, 1999). Apesar dos resultados obtidos nos estudos in vitro não poderem ser extrapolados diretamente para as condições clínicas eles são uma ferramenta para predizer o comportamento desses materiais.

Muitos testes têm sido empregados para mensurações laboratoriais de resistências adesivas, tais como cisalhamento, tração, microtração e microcisalhamento (ARMSTRONG; KELLER; BOYER, 2001; FOONG et al., 2006; MCDONOUGH et al., 2002; TANTBIROJN et al., 2000).

Percebe-se que cada centro de pesquisa utiliza diferentes parâmetros metodológicos para a realização de estudos laboratoriais. Esta variabilidade dificulta a comparação e reprodução de resultados podendo ainda interferir nos valores de 
resistência adesiva obtidos (FOWLER et al., 1992; MARSHALL JR, 1993; VERSILUIS; TANTBIROJN; DOUGLAS, 1997; WATANABE; NAKABAYASHI, 1994).

Quando uma força é aplicada, seja ela de tração ou cisalhamento, à resina composta aderida a uma superfície plana de dentina, a distribuição do estresse ao longo da interface adesiva é altamente não uniforme. Esse estresse é sensível a detalhes de geometria, forma de carregamento, módulo de elasticidade e dimensões do material aderente (VAN NOORT et al., 1989).

A geometria da interface adesiva é um fator que pode ter um significante efeito na mensuração dos valores de resistência adesiva (VAN NOORT et al.,1991). Segundo Phrukkanon, Burrow e Tyas (1998) o uso de espécimes com secção transversal quadrangular não seria o ideal para testes de adesão devido à distribuição desigual do estresse através da interface adesiva.

Baseado nessas informações, entende-se que o teste de microcisalhamento teria uma distribuição mais homogênea de forças ao longo da interface adesiva por apresentarem secção transversal circular (DEHOFF; ANUSAVICE; WANG, 1995; SANO et al., 1994) e seria uma das melhores alternativas para a mensuração de resistências de união entre sistemas adesivos e substratos dentais (MCDONOUGH et al., 2002).

Além disso, o teste de microcisalhamento parece ser o teste mais indicado para estudos de resistência adesiva ao esmalte quando comparado ao teste de microtração (FOONG et al., 2006; SADR et al., 2007; SHIMADA; KIKUSHIMA; TAGAMI, 2002; SHIMADA; TAGAMI, 2003), pois o esmalte, por ser um substrato friável, torna-se suscetível ao preparo de amostras em formato de palito ou ampulheta e a um arrancamento da dentina quando submetido às tensões de tração, devido ao tamanho reduzido do espécime. 
McDonough et al. (2002) ressaltam que uma vantagem do teste de microcisalhamento seria a possibilidade da realização de vários espécimes no mesmo substrato. Graças a esta vantagem um dos fatores de variação deste estudo, a delimitação da área, pôde ser avaliada no mesmo substrato. Desta forma a variabilidade do substrato não poderia ser responsabilizada por diferenças encontradas quando da delimitação da área adesiva, além de colaborar com os baixos valores de desvio-padrão obtidos neste estudo. Øilo e Austrheim (1993) observaram que em seu estudo houve um coeficiente de variação que excedeu $50 \%$ nos valores de adesão encontrados e credita este alto desvio-padrão à impossibilidade de padronização do substrato dentinário.

A demarcação da área adesiva é um parâmetro crucial na obtenção de resistência adesiva (RETIEF, 1991), pois a força de fratura é dada pela unidade de área (PASHLEY et al., 1995). Desta forma a possibilidade de delimitação da área adesiva no teste de microcisalhamento deve ser considerada.

Neste estudo, nos grupos em que a delimitação da área adesiva testada foi realizada, os valores de resistência adesiva obtidos foram aproximadamente $50 \%$ inferiores aos valores encontrados nos grupos em que não se realizou essa delimitação.

Outros estudos que avaliaram a influência da delimitação da área adesiva em ensaios mecânicos (DICKENS; MILOS, 2002; VAN NOORT et al.,1991) encontraram resultados semelhantes aos obtidos no presente estudo e concluíram que a extensão do adesivo além da interface adesiva resultaria em valores artificiais de resistência adesiva. Observa-se na figura 6.1 que quando a delimitação da área não foi realizada a área de arrancamento ultrapassa os limites definidos pelo cilindro de resina composta. 


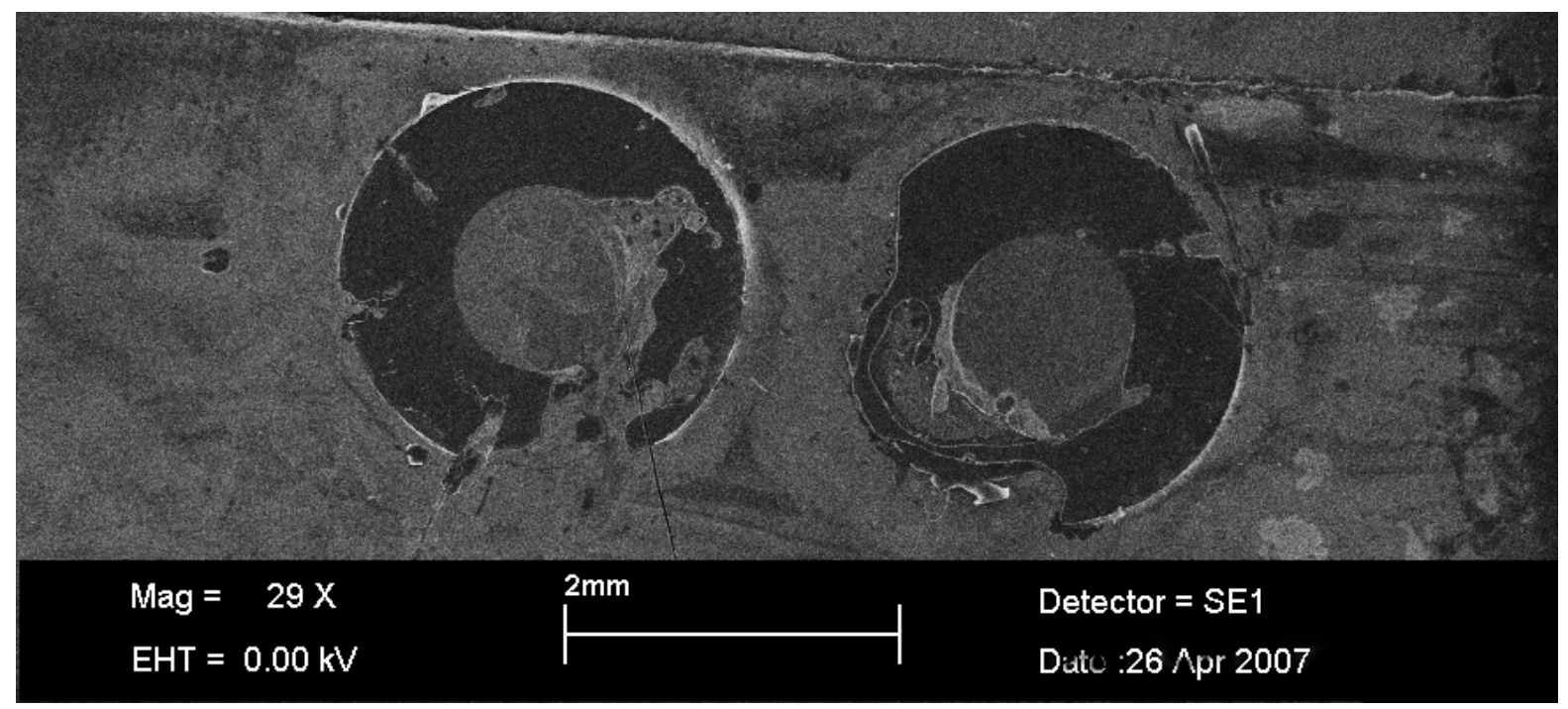

Figura 6.1 - Eletromicrografia evidenciando o arrancamento da camada adesivo além dos limites definidos pelo cilindro de resina composta

Além disso, essa extensão do adesivo poderia interferir no posicionamento do fio utilizado para a aplicação da força de cisalhamento, dificultando o seu correto alinhamento na interface adesiva, contribuindo para a distribuição irregular de tensões. O aumento da distância entre o ponto de aplicação do carregamento e a superfície dentinária geraria a ocorrência de dobramento pelo aumento do momento na aplicação da carga (VAN NOORT et al., 1989).

Ao avaliarem o efeito da delimitação da área adesiva por meio de teste de tração e análise de elementos finitos, Van Noort et al. (1991) encontraram maior incidência de fraturas adesivas quando da delimitação da área adesiva a ser testada. Resultados concordes com os encontrados neste trabalho. Os autores observaram que quando essa delimitação é realizada a concentração de forças ocorre ao redor da circunferência do cilindro de resina composta na interface adesivo-dentina.

Segundo Moll, Fritzenschaft e Haller (2004) outro fator que poderia influenciar nos resultados de resistência adesiva seria a espessura da camada de adesivo. Neste 
estudo observou-se que nos espécimes em que a delimitação da área adesiva não foi realizada a camada de adesivo apresentou-se mais espessa do que nos espécimes em que se realizou a delimitação (Figura 6.2).

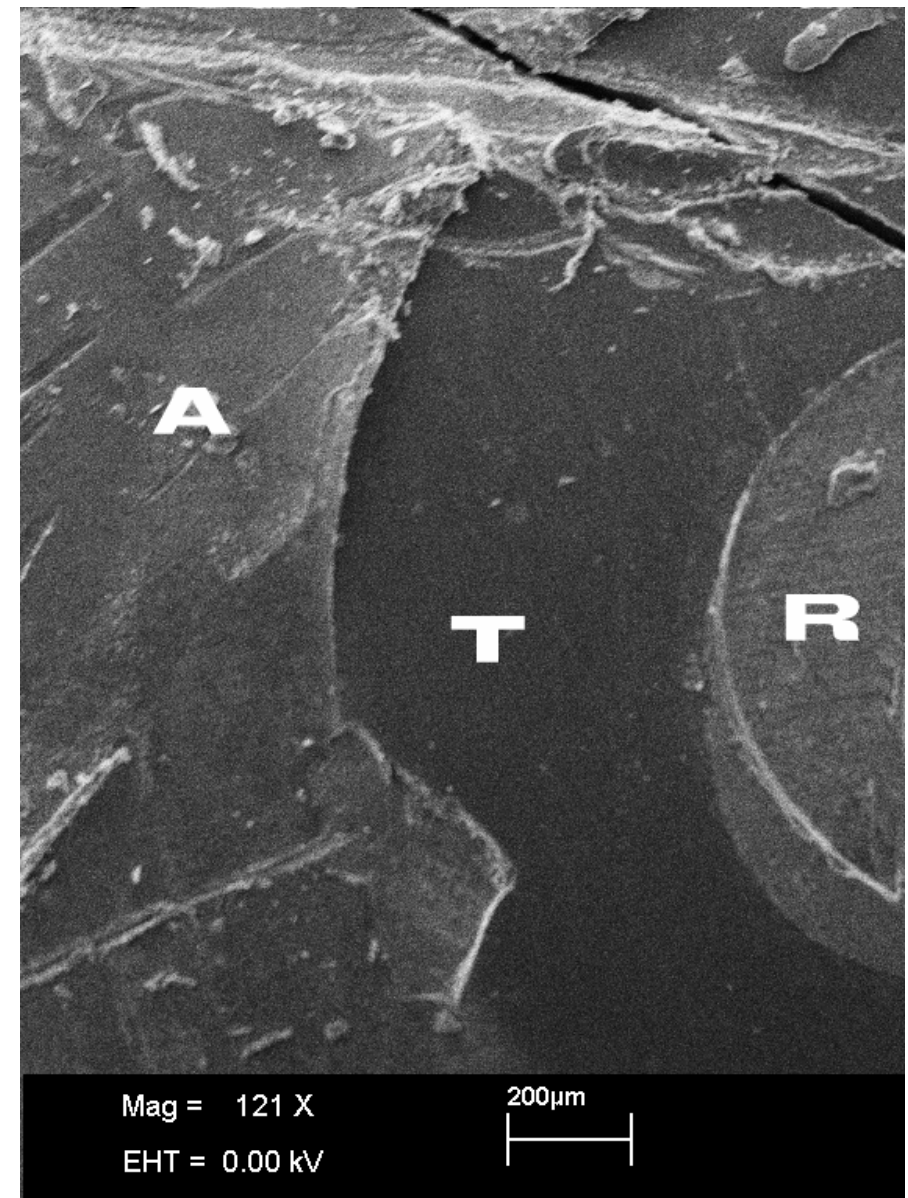

Figura 6.2 - Eletromicrografia de um espécime sem delimitação de área adesiva. (A) camada de sistema adesivo, ( $T$ ) porção ocupada pelo tubo tygon, (R) cilindro de resina composta

Isso porque para que o tubo tygon permaneça em posição durante a confecção dos espécimes ele é colocado sobre a superfície em que o sistema adesivo foi aplicado previamente à fotopolimerização, desta forma há uma concentração de adesivo tanto ao redor quanto no lúmen do tubo. Por possuir espessura reduzida, a fita adesiva 
utilizada para a delimitação da área evitou a concentração dos sistemas adesivos (Figura 6.3).

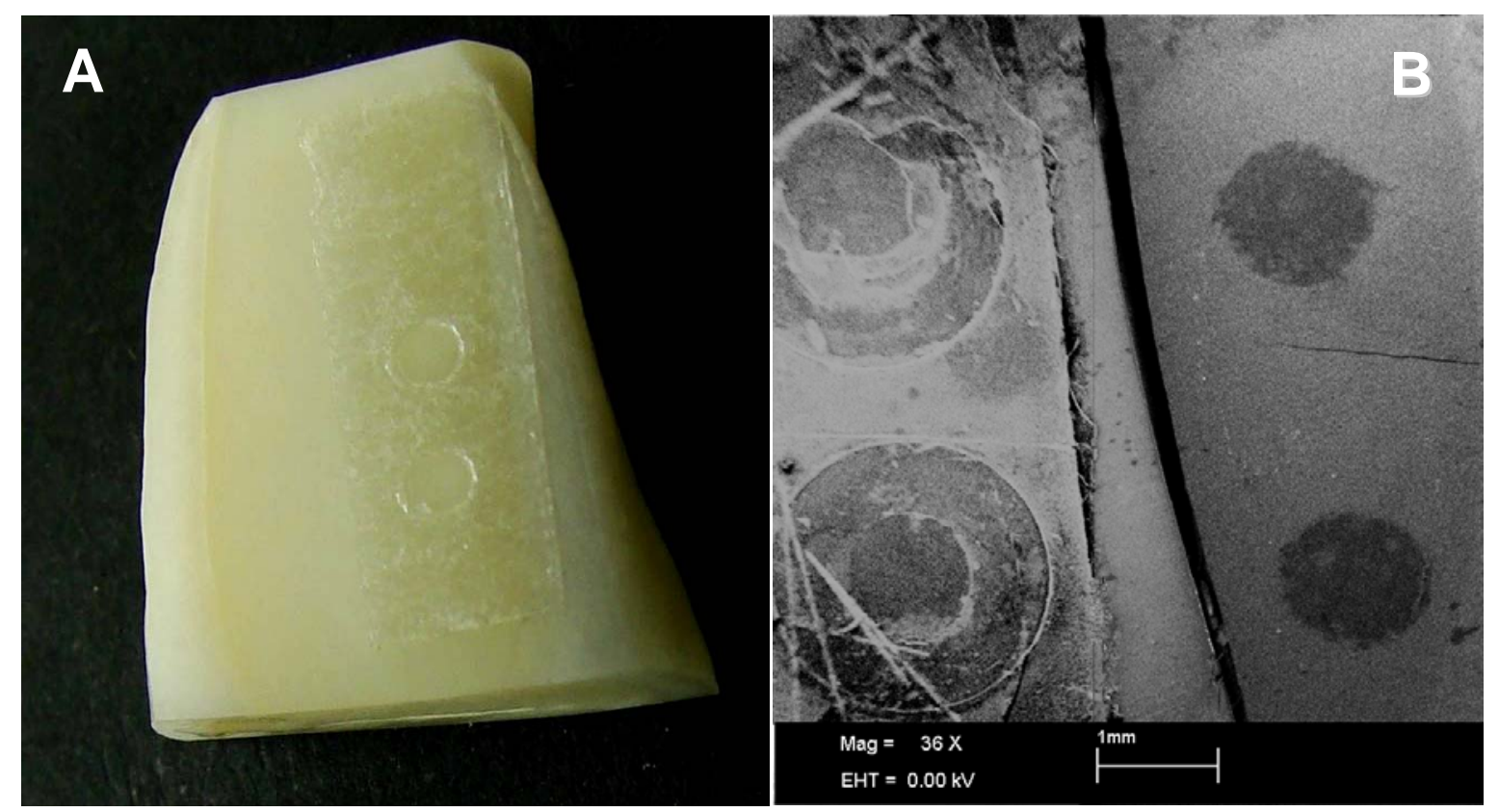

Figura 6.3 - Imagem da amostra experimental (A) e sua respectiva eletromicrografia (B)

Essa modificação da interface adesiva devido ao aumento da irregularidade e da diferença de módulo de elasticidade entre adesivo e resina poderia incorrer na modificação da distribuição de tensões na interface adesiva (DICKENS; MILOS, 2002). Tais características da camada adesiva poderiam explicar a maior incidência de fraturas coesivas nos grupos em que não foi realizada a delimitação da área adesiva.

Testes convencionais ou macro testes foram úteis enquanto a união entre resina e dentina era relativamente baixa (PASHLEY et al., 1999). Com o advento de novos sistemas adesivos as resistências adesivas melhoraram ocasionando maior número de falhas coesivas no substrato dental. 
A ocorrência de fraturas coesivas pode mascarar resultados, pois os valores de tensão nominal são obtidos pela divisão da força aplicada e da área de interface adesiva. Com a fratura do substrato dental esses resultados poderiam ser interpretados equivocadamente como valores de força de união do material restaurador.

No presente estudo verificou-se que a incidência de fraturas coesivas $(22,2 \%)$ foi reduzida em comparação com os outros tipos de fratura $(77,8 \%)$, reafirmando uma das vantagens em se utilizar os microtestes em detrimento dos testes convencionais.

Atualmente os sistemas adesivos dentais empregam duas estratégias distintas para a obtenção de retenções micromecânicas entre resina e dentina. $O$ primeiro método remove completamente a camada de esfregaço e desmineraliza a subsuperfície intacta de esmalte ou dentina por meio de condicionamento ácido (HENOSTROZA, 2003; TAY; PASHLEY, 2001). Esse condicionamento é seguido de lavagem e aplicação de um primer e um adesivo (três passos) ou da aplicação de um sistema que combina primer e adesivo (dois passos), sendo essa estratégia denominada condicione e lave.

A outra estratégia, denominada autocondicionante, é baseada na utilização primers contendo monômeros ácidos que simultaneamente condicionam e preparam a dentina incorporando a camada de esfregaço na camada híbrida. Os primers autocondicionantes eliminam a necessidade de condicionamento, lavagem e secagem da superfície dental, diminuindo o número de passos a serem executados, tornando a técnica menos sensível e susceptível a erros durante o procedimento adesivo (VAN MEERBEEK et al., 2003).

$\mathrm{Na}$ tentativa de tornar a técnica adesiva ainda mais simples foram introduzidos no mercado os adesivos autocondicionantes de passo único ou tudo-em-um que 
combinam a aplicação do condicionador, do primer e do adesivo em um único procedimento (KANEHIRA et al., 2006; PEUMANS et al., 2006).

Para o aumento de sua eficácia os adesivos autocondicionantes de passo único têm se tornado cada vez mais acídicos e hidrofílicos (PASHLEY; TAY, 2001). Entretanto sistemas adesivos muito hidrofílicos tendem a atrair e absorver água difundindo-a através da camada de adesivo, formando canais microscópicos preenchidos por água (árvores de água), proveniente da dentina umedecida ou da própria composição dos adesivos, no interior da camada de adesivo (TAY et al., 2005; TAY; PASHLEY, 2003b; TAY et al., 2005). Adicionalmente, os monômeros tendem a se agrupar antes da polimerização do adesivo formando domínios hidrofílicos em forma de glóbulos (TAY et al., 2004; TAY; PASHLEY, 2003b).

A água é um componente essencial nos adesivos autocondicionantes para que ocorra a ionização necessária para atividade desse tipo de sistema (CHIBA et al., 2006; VAN LANDUYT et al., 2005). Entretanto a presença de água em excesso pode comprometer as propriedades mecânicas do adesivo. A retenção da água residual pode produzir regiões com incompleta polimerização na camada de adesivo (CHERSONI et al., 2004; TAY; PASHLEY, 2003b) além de promover a plastificação de polímeros já formados (TAY et al., 2005).

Neste estudo foram utilizados três sistemas adesivos representantes de diferentes categorias, sendo um do tipo condicione de lave de 2 passos (Adper Single Bond 2), outro do tipo autocondicionante suave $(\mathrm{pH}=1,9)$ de 2 passos (Clearfil SE Bond) e finalmente um do tipo autocondicionante ultrasuave $(\mathrm{pH}=2,7)$ de passo único ou tudoem-um (Clearfil $\mathrm{S}^{3}$ Bond). 
Os valores absolutos de resistência adesiva obtidos neste estudo, independentemente do fator de variação avaliado, se mostraram inferiores a alguns estudos descritos na literatura. Isto provavelmente se deva ao fato deste estudo ter utilizado dentes bovinos como substrato (NAKAMICHI; IWAKU; FUSAYAMA, 1983; RUEGGEBERG, 1991; SAUNDERS, 1988; OESTERLE; SHELLHART; BELANGER, 1998; TAGAMI et al., 1989).

Ainda em relação aos valores absolutos de resistência de união, diferentemente de outros estudos (CARDOSO, 2006; ÇELIK et al., 2006; TAY; PASHLEY, 2001), os valores obtidos para o sistema Adper Single Bond 2 foram inferiores comparados aos sistemas Clearfil SE Bond e Clearfil $S^{3}$ Bond, apesar de estatisticamente similares. Essa diferença se deve, provavelmente, à orientação dos túbulos dentinários do substrato utilizado. A estratégia de adesão empregada pelo sistema condicione e lave (Adper Single Bond 2) é basicamente dependente de embricamento micromecânico por formação de camada híbrida de tags de resina intratubulares (NAKABAYASHI; KOJIMA; MASUHARA, 1982), característica que seria prejudicada em substrato com orientação tubular oblíqua. Já os adesivos autocondicionantes empregados neste estudo têm a capacidade de interagir com o substrato dental por meio de adesão química entre a hidroxiapatita e o monômero ácido 10-MDP presente em sua composição. Assim esses sistemas se mostram menos dependentes da orientação dos túbulos dentinários (SHIMADA; TAGAMI, 2003).

A Figura 6.4 mostra as diferentes interações entre sistema adesivo e substrato dos diferentes grupos estudados. 


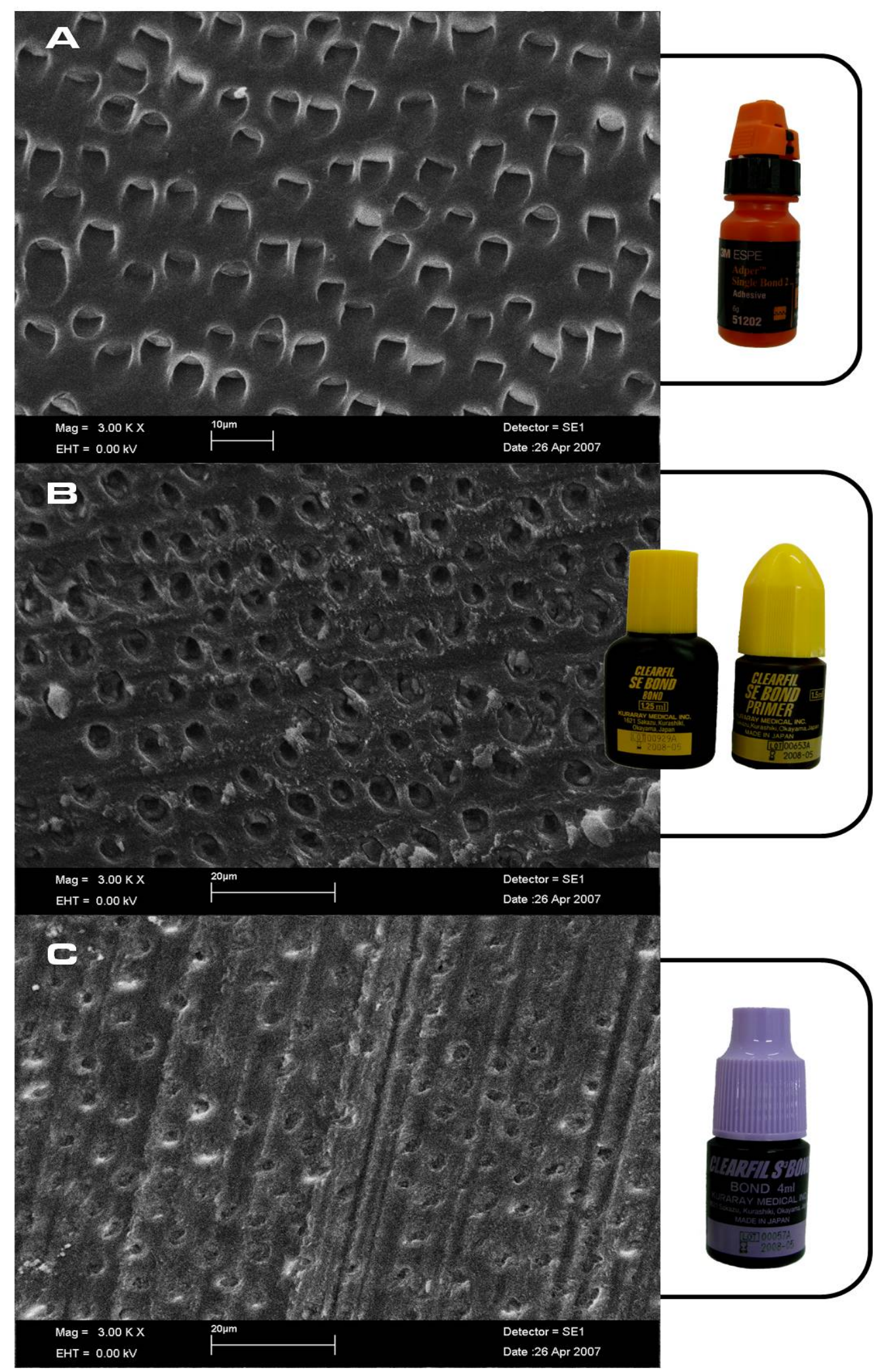

Figura 6.4 - Eletromicrografias das superfícies dentinárias tratadas pelos sistemas adesivos utilizados neste estudo. (A) Adper single Bond 2, (B) Clearfil SE Bond, (C) Clearfil $\mathrm{S}^{3}$ Bond 
Os resultados obtidos mostraram que, quando não foi realizada a delimitação da área adesiva, os sistemas adesivos não apresentaram diferenças estatisticamente significantes entre si. Valores concordes com outro estudo que comparou a efetividade dos mesmos três adesivos por meio de teste de cisalhamento (ÇELIK et al., 2006).

Por outro lado, quando a delimitação da área adesiva a ser testada foi realizada, o sistema Clearfil $S^{3}$ Bond apresentou maiores valores de resistência adesiva em comparação aos outros dois sistemas.

Desta forma percebeu-se uma alteração no ranqueamento dos sistemas adesivos quando se realizou a modificação da metodologia no teste de microcisalhamento.

Segundo a teoria de Griffith (GRIFFITH, 1920; PASHLEY et al., 1995; SANO et al., 1994) um material friável contém pequenas falhas intrínsecas (microtrincas). Quando um esforço de tensão externo é aplicado, as pontas das microtrincas atuam como concentradores de tensão. Como o corpo não pode liberar estas tensões através de deformação plástica, a tensão local na região próxima à ponta da microtrinca mais crítica aumenta até atingir a resistência teórica, causando a ruptura do corpo. Desta forma, as árvores de água poderiam agir como regiões concentradoras de tensões acarretando a iniciação de fraturas que se propagariam até a fratura catastrófica.

Reis et al. (2007) observaram por meio de microscopia eletrônica de transmissão que o sistema Clearfil $S^{3}$ Bond apresentou menor formação de árvores de água quando comparados a outros sistemas autocondicionantes de passo único. Os autores relatam ainda que esse sistema apresenta Tecnologia de Dispersão Molecular, que seria responsável pela manutenção das fases líquidas hidrofílicas e hidrofóbicas 
homogêneas quando da evaporação do solvente, não ocorrendo o fenômeno de separação de fases descrito por Van Landuyt et al. (2005) .

Essas características poderiam ser responsáveis pelo melhor desempenho do sistema adesivo Clearfil $\mathrm{S}^{3}$ Bond quando comparado aos sistemas Single Bond e Clearfil SE Bond que, segundo Tay et al. (2005) apresentam como característica a formação de árvores de água ao longo da camada híbrida.

Talvez essa diferença de comportamento entre os adesivos não tenha sido revelada quando a delimitação de área não foi realizada pois, como discutido anteriormente e observado nas figuras 6.2 e 6.3, nesses grupos não foi possível se obter uma padronização da área adesiva testada. A ausência na constância da área adesiva pode mascarar sutis diferenças entre diferentes sistemas adesivos.

Assim, a delimitação da área adesiva é de fundamental importância na realização do teste de microcisalhamento.

Apesar das limitações creditadas aos testes laboratoriais de resistência adesiva, muitos centros de pesquisa têm direcionado esforços na tentativa de padronização e aperfeiçoamento desses testes que ainda atuam como uma ferramenta para predizer o comportamento clínico de materiais odontológicos. 


\section{CONCLUSÃO}

Os resultados obtidos permitiram-nos concluir que:

7.1 a realização da delimitação da área adesiva no ensaio mecânico de microcisalhamento foi capaz de alterar os resultados de resistência adesiva obtidos, reduzindo seus valores quando comparados com o procedimento sem a delimitação dessa área.

7.2 a modificação da metodologia do ensaio mecânico de microcisalhamento foi capaz de alterar o ranqueamento dos sistemas adesivos analisados.

7.3 a delimitação da área adesiva foi capaz de diminuir a incidência de fraturas coesivas em dentina e aumentar a incidência de faturas adesivas no ensaio mecânico de microcisalhamento. 


\section{REFERÊNCIAS ${ }^{1}$}

Armstrong SR, Keller JC, Boyer DB. Mode of failure in the dentin-adhesive resin-resin composite bonded joint as determined by strength-based (muTBS) and fracture-based (CNSB) mechanical testing. Dent Mater 2001;17(3):201-10.

Buonocore MG. A simple method of increasing the adhesion of acrylic filling materials to enamel surfaces. J Dent Res 1955;34(6):849-53.

Cardoso MV. Estudo da influência de instrumentos e técnicas alternativas de preparo cavitário na resistência de união de sistemas adesivos à dentina [Tese de Doutorado]. São Paulo: Faculdade de Odontologia da USP; 2006.

Çelik EU, Ergucu Z, Turkun LS, Turkun M. Shear bond strength of different adhesives to Er:YAG laser-prepared dentin. J Adhes Dent 2006;8(5):319-25.

Chersoni S, Suppa P, Grandini S, Goracci C, Monticelli F, Yiu C, Huang C, Prati C, Breschi L, Ferrari M, Pashley DH, Tay FR. In vivo and in vitro permeability of one-step self-etch adhesives. J Dent Res 2004;83(6):459-64.

Chiba Y, Rikuta A, Yasuda G, Yamamoto A, Takamizawa T, Kurokawa H, et al. Influence of moisture conditions on dentin bond strength of single-step self-etch adhesive systems. J Oral Sci 2006;48(3):131-7.

DeHoff PH, Anusavice KJ, Wang Z. Three-dimensional finite element analysis of the shear bond test. Dent Mater 1995;11(2):126-31.

De Munck J, Van Landuyt K, Peumans M, Poitevin A, Lambrechts P, Braem M, et al. A critical review of the durability of adhesion to tooth tissue: methods and results. J Dent Res 2005;84(2):118-32.

\footnotetext{
${ }^{1}$ De acordo com Estilo Vancouver . Abreviatura de periódicos segundo base de dados MEDLINE
} 
Dickens SH, Milos MF. Relationship of dentin shear bond strengths to different laboratory test designs. Am J Dent 2002;15(3):185-92.

Foong J, Lee K, Nguyen C, Tang G, Austin D, Ch'ng C, et al. Comparison of microshear bond strengths of four self-etching bonding systems to enamel using two test methods. Aust Dent J 2006;51(3):252-7.

Fowler CS, Swartz ML, Moore BK, Rhodes BF. Influence of selected variables on adhesion testing. Dent Mater 1992;8(4):265-9.

Griffith AA. The phenomena of rupture and flow in solids. Phil Trans Roy Soc London 1920; A221:168-98.

Henestroza MHG, organizador. Adhesion en odontologia restauradora. $2^{\circ}$ ed. Curitiba: Ed. Maio; 2003.

Kanehira M, Finger WJ, Hoffmann M, Endo T, Komatsu M. Relationship between degree of polymerization and enamel bonding strength with self-etching adhesives. J Adhes Dent 2006;8(4):211-6.

Kikushima D, Shimada Y, Foxton RM, Tagami J. Micro-shear bond strength of adhesive systems to cementum. Am J Dent 2005;18(5):364-8.

Marshall GW Jr. Dentin: microstructure and characterization. Quintessence Int 1993;24(9):606-17.

McDonough WG, Antonucci JM, He J, Shimada Y, Chiang MY, Schumacher GE, et al. A microshear test to measure bond strengths of dentin-polymer interfaces. Biomaterials 2002;23(17):3603-8.

Moll K, Fritzenschaft A, Haller B. In vitro comparison of dentin bonding systems: effect of testing method and operator. Quintessence Int 2004;35(10):845-52.

Nakabayashi N, Kojima K, Masuhara E. The promotion of adhesion by the infiltration of monomers into tooth substrates. J Biomed Mater Res 1982;16(3):265-73. 
Nakamichi I, Iwaku M, Fusayama T. Bovine teeth as possible substitutes in the adhesion test. J Dent Res 1983;62(10):1076-81.

Oesterle LJ, Shellhart WC, Belanger GK. The use of bovine enamel in bonding studies. Am J Orthod Dentofacial Orthop 1998;114(5):514-9.

Øilo G, Austrheim EK. In vitro quality testing of dentin adhesives. Acta Odontol Scand 1993;51(4):263-9.

Pashley DH, Carvalho RM, Sano H, Nakajima M, Yoshiyama M, Shono Y, et al. The microtensile bond test: a review. J Adhes Dent 1999;1(4):299-309.

Pashley DH, Sano H, Ciucchi B, Yoshiyama M, Carvalho RM. Adhesion testing of dentin bonding agents: a review. Dent Mater 1995;11(2):117-25.

Pashley DH, Tay FR. Aggressiveness of contemporary self-etching adhesives. Part II: etching effects on unground enamel. Dent Mater 2001;17(5):430-44.

Peumans M, Cardoso MV, Van Landuyt K, De Munck J, Carvalho RCR, Lambrechts P, et al. Effect of smear layer interposition on the bonding effectiveness of adhesives to dentin [abstract D99]. GR Cons 2006;4(1): 239.

Phrukkanon S, Burrow MF, Tyas MJ. The influence of cross-sectional shape and surface area on the microtensile bond test. Dent Mater 1998;14(3):212-21.

Reis AF, Bedran-Russo AK, Giannini M, Pereira PN. Interfacial ultramorphology of single-step adhesives: nanoleakage as a function of time. J Oral Rehabil 2007; 34(3):213-21.

Retief DH. Standardizing laboratory adhesion tests. Am J Dent 1991;4(5):231-6.

Rueggeberg FA. Substrate for adhesion testing to tooth structure - review of the literature. Dent Mater 1991;7(1):2-10. 
Sano H, Shono T, Sonoda H, Takatsu T, Ciucchi B, Carvalho R, et al. Relationship between surface area for adhesion and tensile bond strength-evaluation of a microtensile bond test. Dent Mater 1994;10(4):236-40.

Saunders WP. The shear impact retentive strengths of four dentine bonding agents to human and bovine dentine. J Dent 1988;16(5):233-8.

Sadr A, Ghasemi A, Shimada Y, Tagami J. Effects of storage time and temperature on the properties of two self-etching systems. J Dent 2007;35(3):218-25.

Sadr A, Shimada Y, Tagami J. Effects of solvent drying time on micro-shear bond strength and mechanical properties of two self-etching adhesive systems. Dent Mater. No prelo 2006;17.

Shimada Y, Kikushima D, Tagami J. Micro-shear bond strength of resin-bonding systems to cervical enamel. Am J Dent 2002;15(6):373-7.

Shimada Y, Iwamoto N, Kawashima M, Burrow MF, Tagami J. Shear bond strength of current adhesive systems to enamel, dentin and dentin-enamel junction region. Oper Dent 2003;28(5):585-90.

Shimada Y, Tagami J. Effects of regional enamel and prism orientation on resin bonding. Oper Dent 2003;28(1):20-7.

Sudsangiam S, van Noort R. Do dentin bond strength tests serve a useful purpose? J Adhes Dent 1999;1(1):57-67.

Tagami J, Tao L, Pashley DH, Horner JA. The permeability of dentine from bovine incisors in vitro. Arch Oral Biol 1989;34(10):773-7.

Tantbirojn D, Cheng YS, Versluis A, Hodges JS, Douglas WH. Nominal shear or fracture mechanics in the assessment of composite-dentin adhesion? J Dent Res 2000;79(1):418.

Tay FR, Lai CN, Chersoni S, Pashley DH, Mak YF, Suppa P, et al. Osmotic blistering in enamel bonded with one-step self-etch adhesives. J Dent Res 2004;83(4):290-5. 
Tay FR, Pashley DH. Aggressiveness of contemporary self-etching systems. I: Depth of penetration beyond dentin smear layers.Dent Mater. 2001;17(4):296-308.

Tay FR, Pashley DH. Have dentin adhesives become too hydrophilic. J Can Dent Assoc 2003a;69(11):726-31.

Tay FR, Pashley DH. Water treeing--a potential mechanism for degradation of dentin adhesives. Am J Dent 2003b;16(1):6-12.

Tay FR, Pashley DH, Suh BI, Hiraishi N, Yiu CK. Water treeing in simplified dentin adhesives - déjà vu? Oper Dent 2005;30(5):561-79.

Van Meerbeek B, De Munck J, Yoshida Y, Inoue S, Vargas M, Vijay P, et al. Buonocore memorial lecture. Adhesion to enamel and dentin: current status and future challenges. Oper Dent 2003;28(3):215-35.

Van Landuyt KL, De Munck J, Snauwaert J, Coutinho E, Poitevin A, Yoshida Y, et al. Monomer-solvent phase separation in one-step self-etch adhesives. J Dent Res 2005;84(2):183-8.

Van Noort R, Cardew GE, Howard IC, Noroozi S. The effect of local interfacial geometry on the measurement of the tensile bond strength to dentin. J Dent Res 1991;70(5):88993.

Van Noort R, Noroozi S, Howard IC, Cardew G. A critique of bond strength measurements. J Dent 1989;17(2):61-7.

Versluis A, Tantbirojn D, Douglas WH. Why do shear bond tests pull out dentin? J Dent Res 1997;76(6):1298-307.

Watanabe I, Nakabayashi N. Measurement methods for adhesion to dentine: the current status in Japan. J Dent 1994;22(2):67-72. 
ANEXO A - Dados obtidos pelo teste de microcisalhamento incluindo: resistência adesiva (MPa) e modo de fratura (CD - coesiva de dentina; $A$ - adesiva; $C R$ - coesiva em resina; $\mathrm{M}$ - mista)

\begin{tabular}{|c|c|c|c|c|c|c|}
\hline Sistema Adesivo & & amostra & & & Modc & ratura \\
\hline \multirow{12}{*}{ Adper Single Bond 2} & \multirow{6}{*}{ 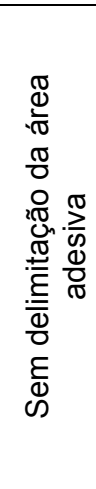 } & 01 & 25,29 & 26,94 & $\mathrm{M}$ & CR \\
\hline & & 02 & 23,75 & 20,67 & $\mathrm{M}$ & CR \\
\hline & & 03 & 27,10 & 24,24 & $M$ & $M$ \\
\hline & & 04 & 24,21 & 26,96 & A & CR \\
\hline & & 05 & 24,70 & 23,34 & $A$ & $M$ \\
\hline & & 06 & 26,40 & 24,37 & $M$ & $M$ \\
\hline & \multirow{6}{*}{ 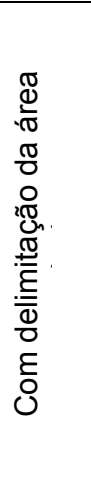 } & 01 & 14,23 & 14,79 & $M$ & CR \\
\hline & & 02 & 10,64 & 8,17 & A & A \\
\hline & & 03 & 16,25 & 18,60 & $M$ & $M$ \\
\hline & & 04 & 15,87 & 14,69 & $M$ & $\mathrm{M}$ \\
\hline & & 05 & 17,98 & 15,43 & A & A \\
\hline & & 06 & 17,82 & 18,50 & $A$ & CR \\
\hline
\end{tabular}




\begin{tabular}{|c|c|c|c|c|c|c|}
\hline Sistema Adesivo & & amostra & \multicolumn{2}{|c|}{ Mpa } & \multicolumn{2}{|c|}{ Modo de fratura } \\
\hline \multirow{12}{*}{ Clearfil SE Bond } & \multirow{6}{*}{ 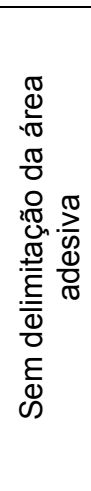 } & 01 & 26,50 & 32,39 & $\mathrm{M}$ & CD \\
\hline & & 02 & 23,28 & 25,23 & $M$ & $M$ \\
\hline & & 03 & 25,60 & 23,37 & $\mathrm{M}$ & $M$ \\
\hline & & 04 & 26,79 & 22,71 & CR & CR \\
\hline & & 05 & 24,33 & 23,62 & CD & $M$ \\
\hline & & 06 & 21,75 & 17,25 & $M$ & $M$ \\
\hline & & 01 & 20,35 & 11,73 & $M$ & $M$ \\
\hline & $\begin{array}{l}\mathbb{\infty} \\
\stackrel{\mathbb{\sigma}}{\mathbb{\sigma}}\end{array}$ & 02 & 14,33 & 11,24 & $\mathrm{M}$ & $M$ \\
\hline & $\begin{array}{l}0 \\
\text { in } \\
\text { in. }\end{array}$ & 03 & 13,62 & 11,67 & $\mathrm{M}$ & A \\
\hline & 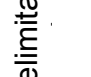 & 04 & 13,58 & 11,63 & $M$ & $M$ \\
\hline & $\begin{array}{l}\text { oे } \\
\text { है }\end{array}$ & 05 & 19,50 & 17,80 & $M$ & $M$ \\
\hline & & 06 & 20,00 & 13,85 & $A$ & $M$ \\
\hline
\end{tabular}

\begin{tabular}{|c|c|c|c|c|c|c|}
\hline Sistema Adesivo & & amostra & \multicolumn{2}{|c|}{ Mpa } & \multicolumn{2}{|c|}{ Modo de fratura } \\
\hline \multirow{12}{*}{ Clearfil $S^{3}$ Bond } & \multirow{6}{*}{ 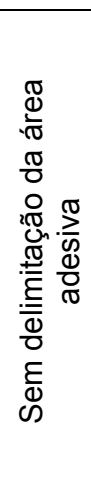 } & 01 & 35,93 & 21,73 & CD & $M$ \\
\hline & & 02 & 32,53 & 36,29 & $C D$ & $M$ \\
\hline & & 03 & 26,73 & 28,05 & $M$ & $M$ \\
\hline & & 04 & 29,20 & 27,56 & CD & CD \\
\hline & & 05 & 25,69 & 29,15 & CR & $\mathrm{M}$ \\
\hline & & 06 & 33,28 & 35,80 & CD & CD \\
\hline & & 01 & 24,16 & 16,69 & $M$ & $A$ \\
\hline & 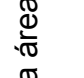 & 02 & 18,30 & 24,52 & $M$ & $M$ \\
\hline & 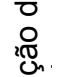 & 03 & 25,34 & 20,76 & $\mathrm{M}$ & $\mathrm{M}$ \\
\hline & 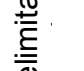 & 04 & 18,66 & 13,83 & $A$ & $A$ \\
\hline & $\begin{array}{l}\text { ठे } \\
\varepsilon \\
\text { ô }\end{array}$ & 05 & 22,88 & 9,80 & $\mathrm{M}$ & $A$ \\
\hline & & 06 & 20,42 & 17,83 & $A$ & $M$ \\
\hline
\end{tabular}

